\title{
Involvement of cyclin-dependent kinase-like 2 in cognitive function required for contextual and spatial learning in mice
}

\author{
Hiroshi Gomi ${ }^{1,2 * \pm}$, Takayuki Sassa ${ }^{2+\ddagger}$ Richard F. Thompson ${ }^{3}$ and Shigeyoshi Itohara ${ }^{2}$ \\ ' Laboratory of Molecular Endocrinology and Metabolism, Institute for Molecular and Cellular Regulation, Gunma University, Maebashi, Japan \\ Behavioral Genetics, RIKEN Brain Science Institute, Wako, Japan \\ ${ }^{3}$ Neuroscience Program, University of Southern California, Los Angeles, CA, USA
}

\section{Edited by:}

Jeansok J. Kim, University of

Washington, USA

\section{Reviewed by:}

Fred J. Helmstetter, University of Wisconsin-Milwaukee, USA

June-Seek Choi, Korea University,

Korea (South)

\section{${ }^{*}$ Correspondence:}

Hiroshi Gomi, Institute for Molecular and Cellular Regulation, Gunma

University, 3-39-15 Showa-machi,

Maebashi, Gunma 371-8512, Japan.

e-mail: hgomi@showa.gunma-u.ac.jp

${ }^{+}$Present address:

Faculty of Pharmaceutical Sciences, Hokkaido University, Japan.

${ }^{\ddagger}$ Hiroshi Gomi and Takayuki Sassa have contributed equally to this work.
Cyclin-dependent kinase-like 2 (Cdkl2) is a cdc2-related serine/threonine protein kinase that is postnatally expressed in various brain regions, including the cerebral cortex, entorhinal cortex, hippocampus, amygdala, and dorsal thalamus. The extremely high $C d k / 2$ expression in these regions suggests that it has a role in cognition and emotion. Recent genetic studies indicate that mutations of $\mathrm{Cdkl}$ family kinases are associated with neurodevelopmental and neuropsychiatric disorders in humans. To elucidate the physiologic role of CdkI2, we behaviorally analyzed CdkI2tacz ${ }^{\mathrm{LacZ}}$ mice lacking CdkI2. CdkI2 ${ }^{\mathrm{LacZ} / \mathrm{LaCZ}}$ mice had reduced latencies to enter the dark compartment after electric footshock in an inhibitory avoidance task and attenuated contextual fear responses when exposed to mild training conditions. Hippocampal spatial learning in the Morris water maze was slightly anomalous with mice exhibiting an abnormal swimming pattern. The aversive response in a two-way avoidance task was slightly, but not significantly, enhanced. On the other hand, Cdk/2 ${ }^{\text {Laczllacz }}$ mice did not exhibit altered sensitivity to aversive stimuli, such as electric footshock and heat, or deficits in the elevated plus maze or rotating rod test. These findings suggest that Cdkl2 is involved in cognitive function and provide in vivo evidence for the function of Cdkl family kinases expressed in terminally differentiated neurons in mice.

Keywords: active avoidance, Cdk12, cdc2-related kinase, cognitive function, contextual fear conditioning, inhibitory avoidance, Morris water maze, Rett syndrome

\section{INTRODUCTION}

Current understanding of the molecular mechanisms of synaptic plasticity emphasizes the important role of phosphorylation of synaptic substrates, including glutamate receptors (Lee, 2006). Phosphorylation of the transcription factor cAMP responsive element-binding protein mediates signaling from the synapse to the nucleus during hippocampal synaptic plasticity (Deisseroth et al., 1996), which is an important process underlying long-term memory formation in diverse animal species (Silva et al., 1998). Phospho-regulation of key proteins is mediated by various kinases, such as mitogen-activated protein kinase (MAPK), $\mathrm{Ca}^{2+} / \mathrm{calmodu}^{-}$ lin-dependent protein kinase II, protein kinase C, cAMP-dependent protein kinase, cGMP-dependent protein kinase, and casein kinase II (Lee, 2006). The heterogeneity of kinases involved in phospho-regulation provides a fundamental basis for the sequential biochemical reactions that underlie the mechanisms of synaptic plasticity.

The cyclin-dependent kinase-like (Cdkl) kinase family comprises five members, Cdkl1 to Cdkl5, and is considered a separate branch of the cyclin-dependent kinase (Cdk) family that is similar to the MAPK family (Taglienti et al., 1996; Malumbres et al., 2009). Although Cdks were originally described as key regulatory elements of the eukaryotic cell cycle (Morgan, 1995), many Cdks are expressed in terminally differentiated cells in the nervous system (Tsai et al., 1993; Grana et al., 1994; Hirose et al., 1997; Lazzaro et al., 1997; LeBouffant et al., 2000) and presumably have roles in processes other than cell-cycle regulation. For example, Cdk5 activity is predominant in the nervous system and has an important role in brain development, neuronal differentiation, neuronal cytoskeletal organization, and regulation of hippocampal synaptic plasticity and learning (Tsai et al., 1993; Ohshima et al., 1996; Hawasli et al., 2007, 2009). Furthermore, activation of the MAPK signaling cascade is involved in long-term facilitation of the sensory to motor synapse in Aplysia and in hippocampal long-term potentiation, water maze learning, and contextual fear conditioning in mammals (Martin et al., 1997; Atkins et al., 1998; Selcher et al., 1999, 2003; Satoh et al., 2007). This evidence suggests that the Cdkl kinase family might be involved in behavioral modification, activity-dependent synaptic plasticity, and learning.

We previously isolated Cdkl2 cDNA from the deep cerebellar nuclei of rabbits undergoing eyeblink conditioning (Gomi et al., 1999). To study the function and transcriptional mechanisms of Cdkl2, we determined the structure of the mouse $C d k l 2$ gene (Sassa et al., 2000) and prepared $C d k l 2$ mutant mice $\left(C d k l 2^{\text {LacZ/ }}\right)$ in which the amino-terminus-coding exons were replaced by LacZ (Sassa et al., 2004). Analysis of LacZ localization demonstrated strong postnatal expression of $C d k l 2$ in several brain regions, including the cerebral cortex, entorhinal cortex, hippocampus, amygdala, and dorsal thalamus, as well as the deep cerebellar nuclei (Sassa et al., 2004), suggesting a potential role of Cdkl2 in cognition and emotion. Among the Cdkl family members, the kinase domains of Cdkl1 and Cdkl3 are closely homologous (58-59\%) to that of Cdkl2 (Yen et al., 1995; Midmer et al., 1999; Haq et al., 2001).Cdkl1 expression in the brain is observed in astrocytes and is thus complementary to $C d k l 2$ expression. $C d k l 3$ transcripts are detected in 
the brain (Yee et al., 2003; Dubos et al., 2008), but the cell type that expresses $C d k l 3$ is not yet known. The expression pattern of Cdkl4 in the nervous system is also not yet characterized in detail. Cdkl5 expression is strongly induced in early postnatal stages, and Cdkl5 is present in mature neurons in the adult brain, but not in astrocytes (Rusconi et al., 2008).

Recent studies demonstrated that mutations of $C d k l$ family members are associated with intellectual and developmental disabilities (IDD) in humans. Dubos et al. (2008) reported that CDKL3, located in chromosome 5 , is disrupted in a patient with mild IDD by a balanced reciprocal translocation between chromosome $\mathrm{X}$ and 5. Mutations in CDKL5/STK9 are associated with X-linked atypical variants of Rett syndrome, a neurodevelopmental disorder characterized by infantile spasms or early-onset epilepsy with IDD (Kalscheuer et al., 2003; Tao et al., 2004; Weaving et al., 2004). CDKL5 binds and phosphorylates DNA methyltransferase 1 in vitro (Kameshita et al., 2008) and seems to function in a molecular pathway common to that of methyl-CpG-binding protein 2, the main cause of Rett syndrome (Mari et al., 2005). Despite the implications of these findings, direct evidence supporting the role of the Cdkl family members in cognition and emotion is largely missing.

In the present study, we tested homozygous mutant mice $\left(C d k l 2^{\text {LacZ/LacZ }}\right)$ in a series of behavioral tasks with cognitive, motor, sensory, and emotional elements to assess the role of Cdkl2 in brain physiology.

\section{MATERIALS AND METHODS ANIMALS}

Cdkl2 mutant mice were generated by deleting a part of the second and third exons and the inter-exonal intron by gene targeting in embryonic stem cells (Sassa et al., 2004). Heterozygous mutant

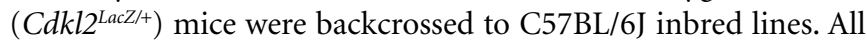
mice were maintained at the animal facilities of RIKEN-BSI according to the institutional guidelines. Housing conditions included a 12-h light/dark cycle, with lights on at 8:00 a.m. and ad libitum food and water. Homozygous mutant ( $\left.C d k l 2^{\text {LacZ/LacZ }}\right)$ and wildtype $\left(C d k l 2^{+/+}\right)$mice used for behavioral analysis were littermates obtained by intercrossing male and female heterozygotes (F1) or backcrossing heterozygotes (N2 to N6) that had been backcrossed to $\mathrm{C} 57 \mathrm{BL} / 6 \mathrm{~J}$ mice. Albino animals were not used in the studies to avoid the potential confounding factor of visual impairment. The generations used for behavioral analysis were: F2 and N2-N3 for the open field test, elevated plus-maze, inhibitory avoidance, contextual fear conditioning, nociceptive sensitivity, conditioned taste aversion (CTA), and rotating-rod tests; and N6 for the Morris water maze (MWM) and two-way active avoidance (TAA) tasks. Mice were used for behavioral analysis at the age of 4-6 months. The sex of the mice used and the order of each testing procedure are shown in Figure 1.

\section{BEHAVIORAL ANALYSIS \\ Open field}

Each mouse was placed in the center of the open field chamber $(60 \mathrm{~W} \times 60 \mathrm{D} \times 50 \mathrm{H} \mathrm{cm}$; OF-3002, O’Hara \& Co. Ltd. Tokyo, Japan $)$ and its activity was recorded for $3 \mathrm{~min}$ using a monochromatic CCD camera (WAT902B, O’Hara \& Co. Ltd., Japan) placed above the chamber. The test was performed in a light condition with

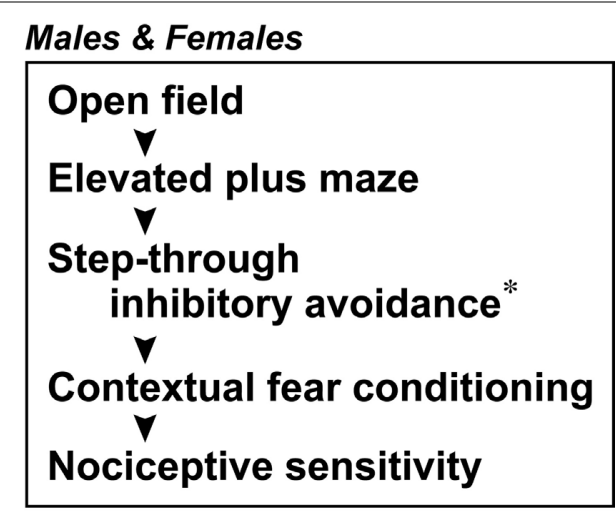

Mixed

Conditioned taste aversion

Males \& Females

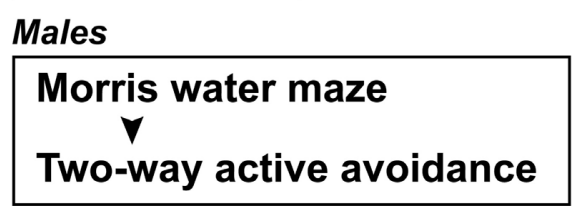

FIGURE 1 |The sex of the mice used for behavioral analysis and the testing procedure order are shown. Each frame indicates an independent group of mice used for the analysis. The asterisk indicates that only male mice were analyzed in the step-through inhibitory avoidance task.

400 lux light illumination. Recorded images were analyzed by the macroprogram NIH Image OF 2.11 (O'Hara \& Co. Ltd.) modified software based on the public domain NIH Image program (developed at the US National Institutes of Health and available on the Internet at http://rsb.info.nih.gov/nih-image/). Parameters analyzed were total distance moved $(\mathrm{cm})$, movement rate $(\mathrm{cm} /$ $\mathrm{min}$ ), and movement path. Stereotyped behaviors in the chamber, including number of rearings, grooming episodes, fecal boli, and urination, were counted manually.

\section{Elevated plus-maze}

The elevated plus-maze apparatus comprised two arms without walls (open arms; $25 \mathrm{~W} \times 8 \mathrm{D} \mathrm{cm}$ ) and two arms with walls (closed arms; $25 \mathrm{~W} \times 8 \mathrm{D} \times 15 \mathrm{H} \mathrm{cm}$ ) and an open roof attached to a central platform $(8 \mathrm{~W} \times 8 \mathrm{D} \mathrm{cm})$ in the form of a cross with $90^{\circ}$ angles, with the open arms across from each other and the closed arms across from each other (CM-3002, O'Hara \& Co. Ltd.). The maze was elevated $50 \mathrm{~cm}$ above the floor. Each mouse was placed on the central platform facing an open arm and its behavior was recorded for $5 \mathrm{~min}$ using a monochromatic CCD camera (WAT902B) placed above the maze. Recorded images were analyzed by the macroprogram NIH Image EP 2.12 (O'Hara \& Co. Ltd.) modified software based on the public domain NIH Image program. Parameters analyzed were total distance moved $(\mathrm{cm})$, total number of arm entries, number of entries into open arms, and the percent time spent on open arms. The observer 
manually recorded the numbers of rearings in the closed arms, head dipping over the sides of the open arms, grooming episodes, fecal boli, and urination.

\section{Step-through inhibitory avoidance}

A step-through type apparatus was used for the inhibitory avoidance test. The apparatus comprised a two-compartment lighted chamber (top dimensions: $12.0 \mathrm{~L} \times 9.8 \mathrm{~W} \times 9.0 \mathrm{H} \mathrm{cm}$, bottom dimensions: $12.0 \mathrm{~L} \times 4.2 \mathrm{~W} \times 9.0 \mathrm{H} \mathrm{cm})$ and dark $(18.0 \mathrm{~L} \times 13.5 \mathrm{~W} \times 11.5 \mathrm{H} \mathrm{cm})$ chamber (PA-3002A, O'Hara \& Co. Ltd.). A 4-cm diameter hole with a guillotine door partitioned the apparatus into the light and dark chambers. The floor of the chamber was constructed from a stainless steel grid (2-mm diameter bars spaced $6 \mathrm{~mm}$ apart). The floor of the dark chamber was connected to a scrambled electric footshock controller (PA-2030A) and an environmental control box (PA-4032). A photo-beam in the dark chamber detected the animal entering from the light chamber and automatically measured the latency (s). After 1-h habituation to the experimental room where the masking noise was applied, each mouse was placed in the lighted chamber facing the dark chamber, and the guillotine door was opened to start an acquisition trial. When the mouse stepped with all four paws into the dark chamber, the guillotine door was closed, the baseline latency was recorded, and a footshock $(0.4 \mathrm{~mA}, 5 \mathrm{~s})$ was administered to the mouse. Five seconds after administering the footshock, the mouse was removed from the chamber and returned to its home cage. The mouse was then again placed in the lighted chamber and the latency to re-enter the dark chamber was measured as a retention trial. Two different animal groups were used for the retention trial. In the first group, step-through latency was measured once $24 \mathrm{~h}$ after footshock. In the second group, step-through latency was measured three times, at $1 \mathrm{~min}, 24 \mathrm{~h}$, and $48 \mathrm{~h}$ after footshock. The maximal step-through latency in the retention trial was $180 \mathrm{~s}$. The baseline, acquisition, and retention trial latencies were recorded.

\section{Contextual fear conditioning}

Contextual fear conditioning and a freezing test were conducted in a small nonreflective white chamber with a stainless steel grid floor (2-mm diameter bars, spaced $7 \mathrm{~mm}$ apart) through which footshocks were delivered $(10 \mathrm{~W} \times 10 \mathrm{D} \times 10 \mathrm{H} \mathrm{cm}$, CL-3002, O'Hara \& Co. Ltd.). The chamber was placed inside a soundproof box $(61 \mathrm{~W} \times 42 \mathrm{D} \times 59 \mathrm{H} \mathrm{cm}, \mathrm{CL}-4210)$ with a ventilation fan providing masking noise, a white fluorescent light $(4 \mathrm{~W})$ on the sidewall, and a monochromatic CCD camera (WAT902B) placed on the ceiling. The chamber was connected to a scrambled electric shock generator (SGA-2010) controlled by a CL-2010 controller (O'Hara \& Co. Ltd.). The CCD camera was connected to a computer and the recorded images were analyzed by a macroprogram NIH Image FZ 2.16 (O'Hara \& Co. Ltd.) modified software based on the public domain NIH Image program. The images from the CCD camera were captured as a series of frames ( 2 frames/s) and saved. An adequate gray scale threshold of the imaged frames was determined to clearly outline the shape of the mouse depending on several parameters; mouse coat color, lighting conditions, and iris setting of the $\mathrm{CCD}$ camera. If the lighting and camera conditions were fixed, the main factor relating to the outline of the mouse shape was mouse coat color. We analyzed the black and/or agouti (brown) colored mice for freezing and a gray scale threshold was determined for each coat color. The software calculated the difference in the outline area (pixels) from frame to frame and this difference was used as an index of animal movement or freezing. Freezing behavior was defined as an outline difference between successive frames smaller than 30 pixels that persisted for more than 2 s (i.e., 4 frames). Percent time freezing for each mouse was calculated as the sum of the time spent freezing divided by trial length. Two different protocols were used for contextual fear conditioning, (I) and (II). In protocol (I), the mice were placed into the shock chamber for $4 \mathrm{~min}$ and subsequently subjected to five footshock trials (0.7-mA intensity for $1 \mathrm{~s}$ with 2 min inter-trial interval [ITI]). Mice were removed from the chamber $2 \mathrm{~min}$ after the last footshock and returned to their home cages. Freezing behavior was monitored during the conditioning phase. The next day, the mice were returned the shock chamber and freezing behavior was monitored for $8 \mathrm{~min}$ (24-h contextual test). In protocol (II), the mice were subjected to a single footshock $(0.35-\mathrm{mA}$ intensity for $3 \mathrm{~s}) 30 \mathrm{~s}$ after being placed into the shock chamber. The mice were removed from the chamber $30 \mathrm{~s}$ after the footshock and returned to their home cages. The next day, the mice were returned to the shock chamber and freezing behavior was monitored for 5 min (24-h contextual test).

\section{Nociceptive sensitivity}

An electric shock sensitivity test and a hot-plate test were performed as tests of nociceptive sensitivity. Each mouse was placed into the same electric footshock chamber used for the contextual fear conditioning (CL-3002, O'Hara \& Co. Ltd.) and given a train of electric shocks (1-s duration) with gradually increasing intensity ranging from $0.1-0.5 \mathrm{~mA}$ at $0.05 \mathrm{~mA}$ intervals. The intensity of the electric shocks that first evoked three typical responses: flinch, vocalization, and jump, were recorded. For the hot-plate test, each mouse was placed in a plastic cylinder (open ends, 12 -cm diameter) on an apparatus maintained at $55^{\circ} \mathrm{C}$ (FHP-450S, FINE Co. Ltd., Japan). The latency to initiate an avoidance behavior (i.e., lick hindpaw, vigorous hindpaw shaking, or jump) was recorded for a maximum of $60 \mathrm{~s}$.

\section{Morris water maze}

Before beginning the MWM task, the mice were handled by the experimenter daily for at least 7 days to reduce the level of stress and acclimate the mouse to the experimenter. The training apparatus was a circular white vinyl chloride pool $(100-\mathrm{cm}$ diameter and 30-cm high, WM-3002H, O'Hara \& Co. Ltd.). The pool was located $80 \mathrm{~cm}$ above the floor. An animal swimming in the pool could see a number of items that remained in a constant location with respect to the pool. The water was maintained at $25^{\circ} \mathrm{C}$ with a thermo-heater. The goal platform was $10 \mathrm{~cm}$ in diameter. The top of the platform was located $0.8 \mathrm{~cm}$ below the surface of the water. One of the four starting positions was chosen randomly for each trial. In the hidden-platform test, mice were given 4 trials a day for seven consecutive days. Prior to the first trial on the first day, each mouse was given a pre-training trial to acclimate to the water and the platform by placing the mouse on the platform for $30 \mathrm{~s}$, followed by being placed in the water to swim for $30 \mathrm{~s}$ and then climbing onto the platform. After this pre-training, each mouse was placed on the platform for $30 \mathrm{~s}$ and then lifted from the platform and placed into the water, facing a pool wall at the start position to start the trials. 
The escape latency (s) required to locate the platform was recorded for each trial. The mouse was allowed a maximum of $60 \mathrm{~s}$ of swimming to find the platform. If the mouse did not find the platform within $60 \mathrm{~s}$, the experimenter guided it to the platform. The mouse remained on the platform for the 30-s ITI. After the last trial on the last training day, the mouse was given a probe trial. During the probe trial, the escape platform was removed from the pool and the mouse was allowed to swim for $60 \mathrm{~s}$. A monochromatic CCD camera (WAT902B) was placed above the pool to record the swimming trials. Recorded images were analyzed by the macroprogram, NIH Image WMH2.10 (O’Hara \& Co. Ltd.) modified software based on the public domain NIH Image program. In the training trials, the escape latency and swimming distance were calculated from the image analysis. In the probe trial, the time the mouse spent in each quadrant and the number of times the mouse crossed the exact location where the platform had been during the training trials were determined from image analysis. After the hidden-platform test, the mouse was given a visible-platform test, 4 trials a day for three consecutive days. In the visible-platform test, a platform with a flag was used. The positions of the platform and starting place were randomly varied among four possible places in each trial. The other procedures used in the visible-platform test were the same as described for the hidden-platform test.

\section{Rotating-rod}

The apparatus (Ugo Basile Biological Research Apparatus, Italy) used for the rotating-rod test consisted of a gridded plastic roller (3-cm diameter, $5.5-\mathrm{cm}$ long) that was flanked by two round plates (30-cm diameter) to prevent the animals from escaping. The roller was driven at $17 \mathrm{rpm}$. Each mouse was placed on the rotating rod and the time it remained on the rod was automatically measured. We used two protocols for the test, (I) and (II). In protocol (I), each mouse was trained once per day for five consecutive days. The maximum time allowed on the rotating-rod was $300 \mathrm{~s}$. In protocol (II), mice were given several trials each on 1 day until they could stay on the rod for at least $60 \mathrm{~s}$. The training was performed daily for three consecutive days.

\section{Conditioned taste aversion}

For CTA, each mouse was single-housed in a cage $(17 \mathrm{~W} \times 28 \mathrm{D} \times 12 \mathrm{H} \mathrm{cm})$. After 3 days of individual housing, the mice were trained to drink water from two equal water-supplying bottles set within the cage for 8 days (training) prior to conditioning. After training, the mice were deprived of water for $24 \mathrm{~h}$. On day 9 (conditioning day 1 ), the mice were supplied with two bottles containing $5 \mathrm{mM}$ saccharin sodium solution instead of water for $20 \mathrm{~min}$. Immediately thereafter, the mice were injected intraperitoneally with either $0.15-\mathrm{M}$ lithium chloride ( $\mathrm{LiCl} ; 2 \%$ of body weight) as a malaise-inducing agent or saline as a control. After treatment, the mice were deprived of water for $24 \mathrm{~h}$ and the conditioning was repeated the next day (day 10, conditioning day 2). On day 11 (rest day), the mice were presented with water in the same way as on the training days and their health status was checked. CTA-I was tested on days 12,13, and 14. In this test, each mouse was presented with two bottles for $24 \mathrm{~h}$, one containing saccharin and the other containing water, and consumption was measured by weighing the bottles before and after the test. The two bottle positions were switched each test day to avoid the effects of a spatial cue bias. On days 15 to 21 (retention days), the mouse was presented with two water bottles. CTA-II was tested on days 22, 23, and 24 as described for the CTA-I. The preference score was defined as (saccharin consumption)/(water plus saccharin consumption) and the score was calculated for both CTA-I and -II. If the mice preferred saccharin over water, the score was greater than 0.5. Data from CTA-I and -II were treated as parameters of middle- and long-term memories, respectively.

\section{Two-way active avoidance}

The apparatus for the TAA comprised two identical photo-beam type shuttle boxes $(30 \mathrm{~W} \times 9 \mathrm{D} \times 15 \mathrm{H} \mathrm{cm}, \mathrm{AA}-3202$, O'Hara $\&$ Co. Ltd.) enclosed in two soundproof chests $(61 \mathrm{~W} \times 42 \mathrm{D} \times 59 \mathrm{H} \mathrm{cm}$, AO-4210), a scrambled electric footshock generator (2CH type, SGA-2020), and a scheduler interface (AA-1020T) controlled by a computer program. The two compartments of the shuttle box were divided with a central inverted U-shaped gate. Photo-beams set in both compartments ( $9 \mathrm{~cm}$ from the central gate) detected animal movement from one chamber to the other. The soundproof chest contained a ventilation fan that also provided a masking sound. The conditioned stimulus (CS) was a tone $(600 \mathrm{~Hz}, 60 \mathrm{~dB}, 8 \mathrm{~s})$. The unconditioned $0.2-\mathrm{mA}$ footshock stimulus (US) was supplied via the stainless steel floor grid (2-mm diameter bars, spaced $6 \mathrm{~mm}$ apart) for 3 s coterminating with the tone. One trial consisted of a 22-s ITI, a CS, and an US. If the mouse crossed the central gate to the opposite compartment and broke the sensor photo-beam within $5 \mathrm{~s}$ after the CS onset, the stimulus was terminated and no shock was delivered (avoidance response; AR). A crossing response that occurred during the shock terminated both the tone and shock (escape response; ER). If the mouse failed to cross during the entire tone-shock trial, the tone and shock were terminated after 8 s. A crossing response during the ITI was recorded as a non-effective response. Each mouse was given 30 trials per day for three consecutive days. The percentage of AR and average AR latency (s) was analyzed.

\section{HISTOLOGIC ANALYSIS}

Adult mice (2- to 3-months old) were deeply anesthetized by intraperitoneal injection of sodium pentobarbital $(0.1 \mathrm{mg} / \mathrm{g}$ body weight). For paraffin sections, mice were first intracardially perfused with $10 \mathrm{ml}$ of saline and then with $100 \mathrm{ml}$ of fixative [ $4 \%$ paraformaldehyde in 0.1-M phosphate buffer ( $\mathrm{pH} 7.3)]$ at $4^{\circ} \mathrm{C}$. Brain tissues were dissected into small blocks (5-mm thick) and postfixed in the same fixative overnight. Tissue blocks were dehydrated and embedded in paraffin. Coronal sections (3- to 4- $\mu \mathrm{m}$ thick) were stained with hematoxylin-eosin (H-E) or processed for immunohistochemistry. Deparaffinized sections were autoclaved in Milli-Q water at $121^{\circ} \mathrm{C}$ for $5 \mathrm{~min}$. Immunohistochemistry was performed with the avidin-biotin-peroxidase technique using the Vectastain Elite-ABC kit (Vector Laboratories, Burlingame, CA, USA). Mouse monoclonal anti-neurofilament $2 \mathrm{H} 3$ antibody (1:100 hybridoma supernatant; Developmental Studies Hybridoma Bank, Iowa City, IA, USA) and anti-calbindin D antibody (1:100; C-8666, Sigma-Aldrich, St. Louis, MO, USA) were used for immunohistochemistry. Stained sections were viewed with a microscope (Leica Microsystems, Wetzlar, Germany). For LacZ expression analysis, horizontal and coronal brain slices (100- to $300-\mu \mathrm{m}$ thick) were 
prepared using a microslicer DTK-1000 (Dosaka EM, Kyoto, Japan). Detailed procedures of slice preparation and staining were described previously (Sassa et al., 2004).

\section{STATISTICAL ANALYSIS}

Values in tables and graphs are expressed as means \pm SEM. Statistical analysis was conducted using StatView J-4.5 (Abacus Concepts, Piscataway, NJ, USA). Data were analyzed by an analysis of variance (ANOVA), unpaired Student's $t$-test, Chi-square test, or MannWhitney $U$-test. The Mann-Whitney $U$-test was used when the distribution of the samples was not normally distributed. Statistical significance was set at $P<0.05$.

\section{RESULTS}

Prior to the behavioral analyses, we extensively examined the brain structures of the $C d k l 2^{\text {LacZ/LacZ }}$ mice. Gross brain anatomy, assessed by $\mathrm{H}$-E staining, of $C d k l 2^{\text {LacZ/LacZ }}$ mice did not differ from that of $\mathrm{Cdkl}^{+/+}$mice. Immunohistochemistry using anti-neurofilament and anti-calbindin-D antibodies revealed no obvious morphologic abnormalities of the axons and dendrites from neurons in the cerebral cortex, hippocampus, amygdala, or cerebellum of $C d k l 2^{\text {LacZ/LacZ }}$ mice (Figure 2).

We then analyzed $C d k l 2$ expression in the brain of $C d k l 2^{\text {LacZ/LacZ }}$ mice. As previously reported in $C d k l 2^{L a c Z /+}$ mice (Sassa et al., 2004), the $L a c Z$-reporter was expressed in neurons in various brain regions, including the olfactory bulb, caudate-putamen, cerebral cortex, hippocampus, thalamic nuclei, amygdaloid nuclei, entorhinal cortex, and deep cerebellar nuclei (Figure 3). LacZ expression was strongest in layers II-III and V-VI of the cerebral cortex and entorhinal cortex, stronger in the hippocampus and thalamic nuclei, and moderate in the caudate-putamen, amygdala, and deep cerebellar nuclei.
To evaluate locomotor and exploratory activities in $C d k l 2^{\text {LacZ/LacZ }}$ mice, we performed an open field test. Mice were placed in the center of the open field chamber for $3 \mathrm{~min}$. Distance moved in the chamber and time spent in each region of the chamber were measured and stereotyped behaviors were counted (Table 1). Distance moved in the chamber did not differ significantly between genotypes. The time-spent pattern in each region showed that both genotypes equally avoided the center zone of the open field. Although male $C d k l 2^{\text {LacZ/LacZ }}$ mice tended to have an increased number of rearings $(P=0.0607)$, the difference between genotypes was not significant. The number of rearings, grooming episodes, fecal boli, and urinations did not significantly differ between genotypes.

Anxiety-related behavior was then evaluated in an elevated plusmaze (Lister, 1987). Mice were placed in the center of elevated plus-maze for $5 \mathrm{~min}$, and the number of entries into the arms, time spent in each compartment, and distance moved were measured (Table 1). Both genotypes tended to avoid the open arms, as assessed by counting the number of open arm entries and time spent on open arms. Although female $C d k l 2^{\text {LacZ/LacZ }}$ mice tended to move a greater total distance $(P=0.0972)$, the difference between genotypes was not significant. The stereotyped behaviors, including rearings on the closed arms, head dipping on open arms, fecal boli, and urinations, did not differ significantly between genotypes. These results suggest that the affective state of the $C d k l 2^{\text {LacZ/LacZ }}$ mice is not appreciably altered.

To evaluate context-dependent avoidance activity, we performed a step-through inhibitory avoidance test (Lorenzini et al., 1996). We measured the retention latencies in two independent experiments. In the first experiment, the retention latency to enter the dark chamber was measured $24 \mathrm{~h}$ after footshock in $C d k l 2^{+/+}$mice $(n=16)$ and $C d k l 2^{\text {LacZ/LacZ }}$ mice $(n=14)$. The baseline latency to enter the dark

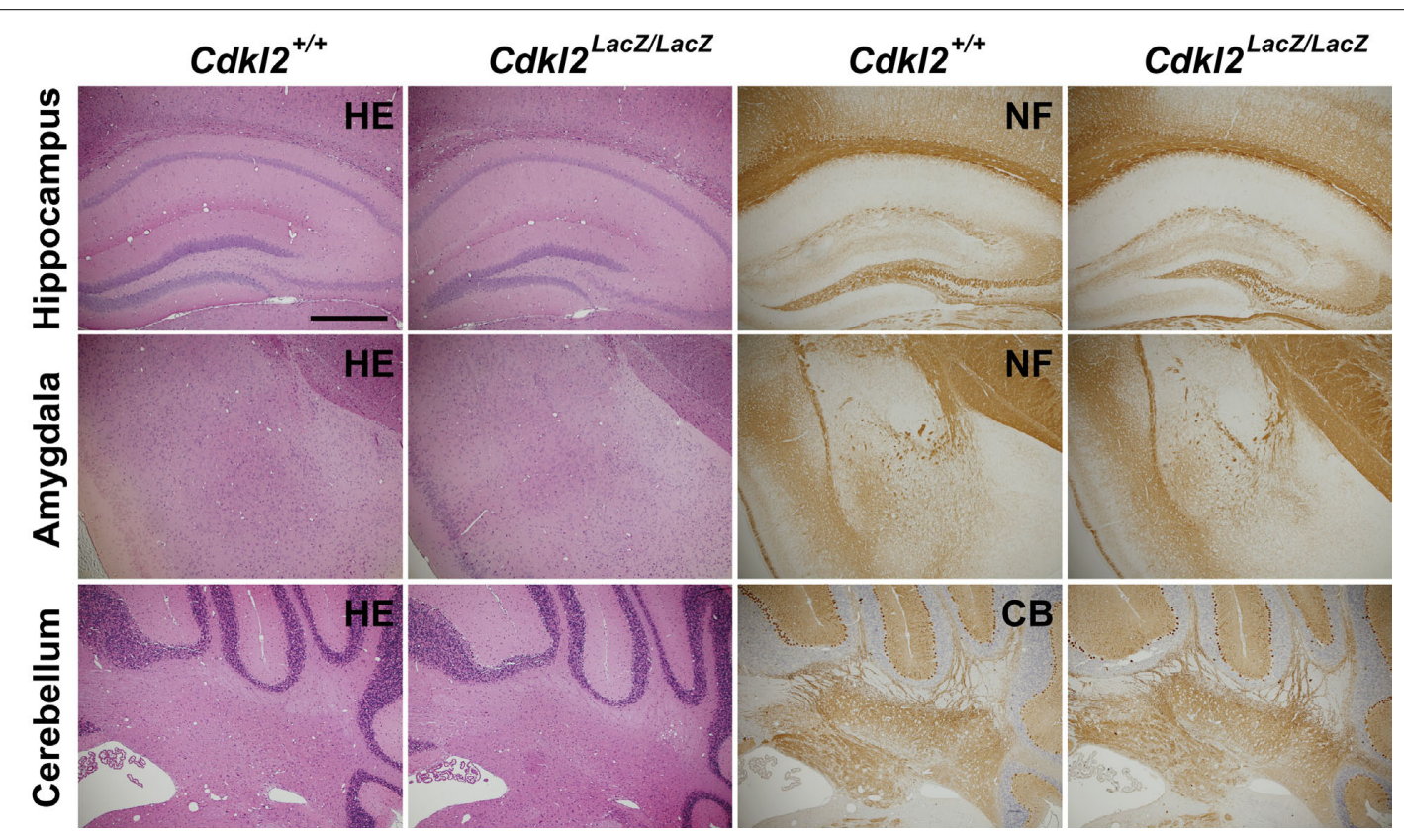

FIGURE 2 | Morphologic analysis. $\mathrm{H}$-E-staining (HE) and immunohistochemistry for neurofilament (NF) and calbindin-D (CB) in coronal brain sections of Cdkl2 ${ }^{+/+}$and Cdkl2 $2^{\text {Lacz/LacZ }}$ mice. Scale bar: $500 \mu \mathrm{m}$. 


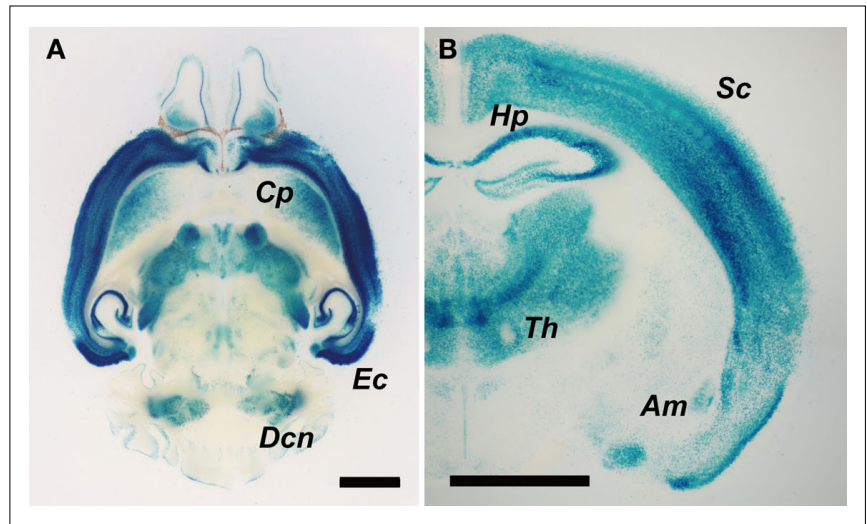

FIGURE 3 | LacZ expression in the brain of Cdkl2 ${ }^{\text {LacZ/LacZ }}$ mice.

(A) Horizontal (300- $\mu \mathrm{m}$ thick) and (B) coronal brain slices (100- $\mu \mathrm{m}$ thick) were prepared using a microslicer and stained with X-gal solution for $6 \mathrm{~h}$ at $37^{\circ} \mathrm{C}$. Abbreviations: $C p$, caudate-putamen; $E_{c}$, entorhinal cortex; Dcn, deep cerebellar nuclei; Sc, somatosensory cortex; Hp, hippocampus; Th, thalamic nuclei; Am, amygdala. Scale bar: $2 \mathrm{~mm}$.

chamber was not different between the two genotypes. Although the retention latency of $C d k l 2^{L a c Z / L a c Z}$ mice tended to decrease in the 24-h retention test, the difference between $C d k l 2^{+/+}$and $C d k l 2^{L a c Z / L a c Z}$ mice was not significant (Figure 4A, $P=0.0745$ ). The percentage of $C d k l 2^{\text {LacZ/LacZ }}$ mice that did not enter the dark compartment (nonstep-through) also tended to decrease (Figure 4B, $P=0.0708$ ). On the other hand, in the second experiment, the retention latency to enter the dark chamber was measured three times ( $1 \mathrm{~min}, 24 \mathrm{~h}$, and $48 \mathrm{~h})$ after footshock in $C d k l 2^{+/+}$mice $(n=29)$ and $C d k l 2^{\text {LacZ/LacZ mice }}$ $(n=23)$. The baseline latency to enter the dark chamber was not different between the two genotypes. The retention latencies measured at $1 \mathrm{~min}, 24 \mathrm{~h}$, and $48 \mathrm{~h}$ after footshock in $C d k l 2^{\text {LacZ/LacZ }}$ mice were significantly shorter than those of $C d k l 2^{+/+}$mice (Figure 4C). The percentages of non-step-through in $C d k l 2^{\text {LacZ/LacZ }}$ mice were also significantly lower than those of $C d k l 2^{+/+}$mice in the 1-min and 24-h retention tests (Figure 4D). The values of both parameters,

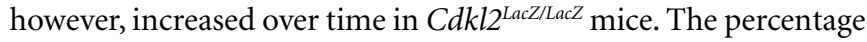
of non-step-through was significantly increased in the 48-h retention test compared to the 1 -min retention test $(P=0.0104)$.

We examined contextual fear conditioning to evaluate contextdependent learning in $C d k l 2^{\text {LacZ/LacZ }}$ mice. We used two different protocols with strong and weak conditioning stimuli. In protocol (I), female mice were given five repeated footshocks 4 min after placement into the shock chamber. Thus, a strong CS and US were used. Pre-shock baseline freezing was not significantly different between $C d k l 2^{+/+}(n=15)$ and $C d k l 2^{\text {LacZ/LacZ }}(n=15)$ mice (Figure 5A). During the 2-min interval after footshock, both $\mathrm{Cdkl2}^{+/+}$and $C d k l 2^{\text {LacZ/LacZ }}$ mice exhibited significant increases in freezing behavior as the conditioning procedure progressed (approximately $85 \%$ freezing after the 5 th shock). Twenty-four hours later, the mice were returned to the shock chamber and freezing behavior was measured (24-h contextual test). While the level of the overall freezing behavior in $C d k l 2^{\text {LacZ/LacZ }}$ mice was similar (approximately $80 \%$ ) to that in $C d k l 2^{+/+}$mice, freezing behavior was significantly reduced in $C d k l 2^{\text {LacZ/LacZ }}$ mice during the initial 3 min of testing (Figure 5B, $P=0.0385$ ). In protocol (II), in which the training protocol was milder than that of protocol (I), male $\operatorname{Cdkl2}^{+++}(n=21)$ and $C d k l 2^{\text {LacZ/LacZ }}(n=19)$ mice were given a single footshock $30 \mathrm{~s}$ after being placed into the chamber. The freezing behavior of $C d k l 2^{\text {LacZI }}$ ${ }^{L a c Z}$ mice in the 24-h contextual test was significantly decreased compared to that of $C d k l 2^{+/+}$mice (Figure 5C, $P=0.0022$ ). The pre-shock baseline freezing, however, was significantly different between in $C d k l 2^{+/+}$and $C d k l 2^{\text {LacZ/LacZ }}$ mice $(P=0.0119)$. Because these mice had previously undergone inhibitory avoidance testing, the deficit in $C d k l 2^{\text {LacZ/LacZ }}$ mice observed in the 24 -h contextual test was likely due to both generalization from the inhibitory avoidance task and new learning.

To evaluate nociceptive sensitivity, we measured nociceptive threshold for electric shock and heat stimuli (Table 2). First, we determined the minimum current $(\mathrm{mA})$ required to elicit three typical reactions of mice to footshock, flinch, vocalization, and jump (Kim et al., 1991). Cdkl2 LacZ/LacZ mice did not differ from $\mathrm{Cdkl2}{ }^{+/+}$mice in their responses to footshock for any of these three responses. We then measured the reaction latency (s) of mice to display avoidance behavior (i.e., lick hindpaw, vigorous hindpaw shaking, or jump) on the hot-plate at $55^{\circ} \mathrm{C}$. $C d k l 2^{\text {LacZ/LacZ }}$ and $C d k l 2^{+/+}$mice exhibited comparable sensitivity to heat stimulus. Thus, nociceptive sensitivity in $C d k l 2^{\text {LacZ/LacZ }}$ mice was equivalent to that in $\mathrm{Cdkl}^{+/+}$mice.

We investigated whether $C d k l 2^{\text {LacZ/LacZ }}$ mice exhibit altered hippocampal-dependent learning in the MWM (Morris et al., 1982). $C d k l 2^{+/+}(n=14)$ and $C d k l 2^{\text {LacZ/LacZ }}(n=15)$ mice were trained for 7 days in the hidden platform test with 4 trials per day. During the training period, both $C d k l 2^{+/+}$and $C d k l 2^{\text {LacZ/LacZ }}$ mice exhibited improved performance in finding the hidden platform (Figure 6A). Escape latency (s) and swimming distance $(\mathrm{cm})$ did not differ significantly between genotypes, but the $C d k l 2^{\text {LacZ/LacZ }}$ mice swam significantly slower than the $C d k l 2^{+/+}$mice during the training trials. In the probe test, both $C d k l 2^{+/+}$and $C d k l 2^{\text {LacZ/LacZ }}$ mice performed selective searching in the target quadrant with equal percentage of time swimming, but $C d k l 2^{\text {LacZ/LacZ }}$ mice exhibited significantly fewer crossings of the platform location compared to $C d k l 2^{+/+}$mice (Figure 6B). Furthermore, $C d k l 2^{L a c Z / L a c Z}$ mice spent a significantly higher percentage of time swimming along the pool-wall and swam slower. In the visible platform test, the $C d k l 2^{\text {LacZ/LacZ }}$ mice consistently swam slower than the $C d k l 2^{+/+}$mice, but there was no effect of genotype on locating the visible platform (Figure 6C).

Although the $C d k l 2^{\text {LacZ/LacZ }}$ mice swam slower during the MWM, no apparent motor deficit in rotating-rod test was observed in $C d k l 2^{\text {LacZ/LacZ }}$ mice (Figure 7). We used two experimental protocols in the rotating-rod test (Shibuki et al., 1996). In protocol (I), male mice were trained once per day for five consecutive days on the rotating-rod with an upper limit of 300-s. Retention time (s) on the rod of $C d k l 2^{+/+}(n=15)$ and $C d k l 2^{\text {LacZ/LacZ }}(n=15)$ mice is shown in Figure 7A. Most mice of both genotypes learned to stay on the rod by the fifth session and there was no significant difference between genotypes. In protocol (II), female mice were given multiple training trials in a single day for three consecutive days until they could stay on the rotating-rod for more than $60 \mathrm{~s}$ and the number of trials required was counted for three consecutive days (Figure 7B). Both $C d k l 2^{+++}(n=15)$ and $C d k l 2^{\text {LacZ/LacZ }}(n=14)$ mice learned the task and there was no significant difference between genotypes. Body weight of the animals examined for the rotating-rod test was 
Table 1 | Measurement of animal behavior in open field and elevated plus-maze.

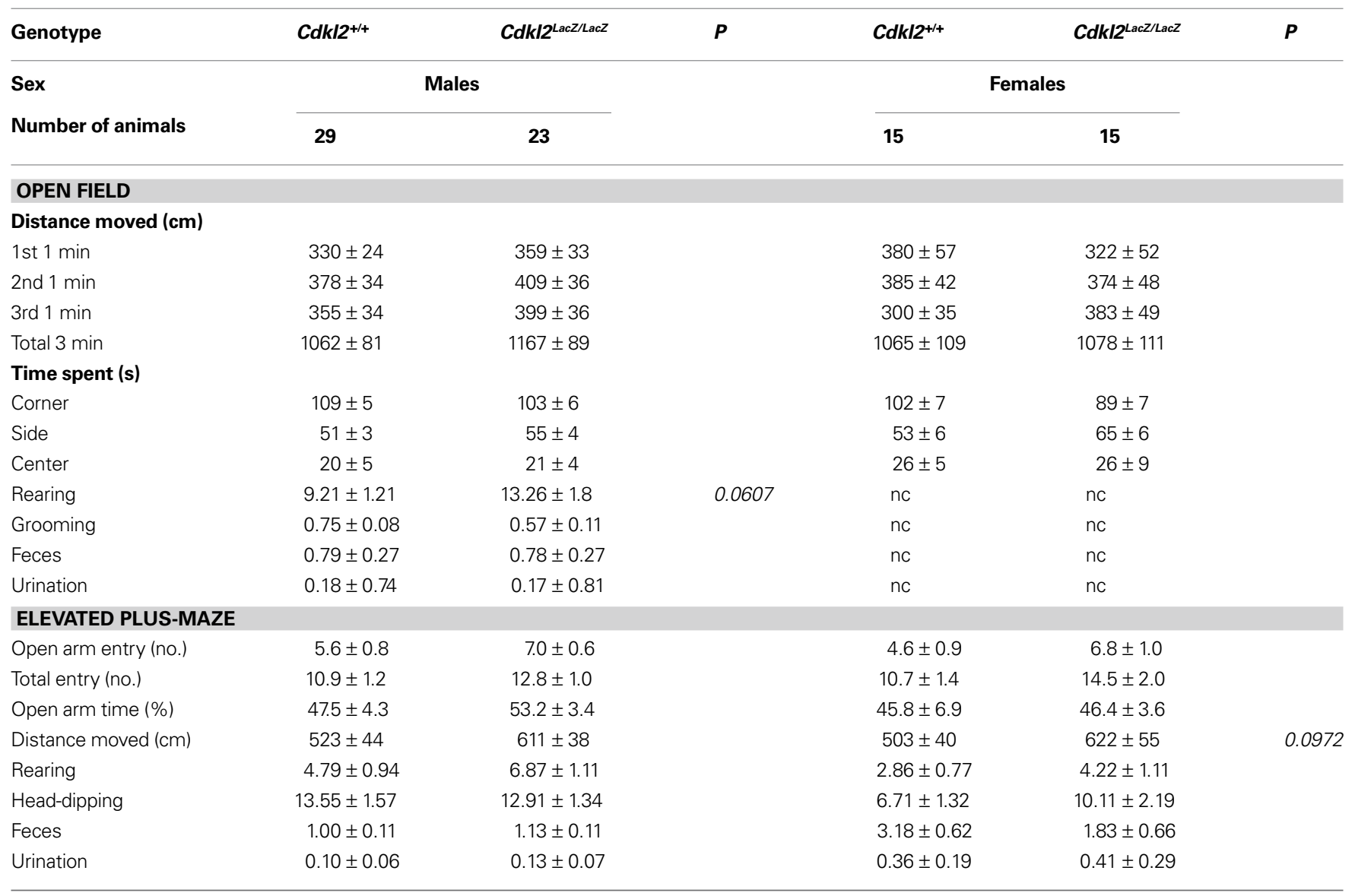

Blank space in P-value columns indicates $P>0.1$ (unpaired Student's t-test). Data are presented as mean \pm SEM; nc, not counted.

not significantly different between genotypes ( $C d k l 2^{+/+}$mice: male, $26.9 \pm 3.0 \mathrm{~g}$ and female, $21.3 \pm 2.7 \mathrm{~g}$ vs. $\mathrm{Cdkl} 2^{\mathrm{LacZ} / \mathrm{LacZ}}$ mice: male, $27.8 \pm 3.9 \mathrm{~g}$ and female, $19.5 \pm 2.4 \mathrm{~g})$. Thus, $C d k l 2^{\text {LacZ/LacZ }}$ mice did not show any apparent deficit in motor coordination in a constantspeed rotating rod task.

We then evaluated the behavior of $C d k l 2^{\text {LacZ/LacZ }}$ mice in an amygdala-dependent task, CTA (Nachman and Ashe, 1974; Yamamoto and Fujimoto, 1991; Yamamoto et al., 1994). In CTA, animals learn to associate a taste CS and visceral malaise-inducing US. A strong aversive response can be elicited in mice by paired administration of saccharin flavor and a malaise-inducing intraperitoneal injection of $\mathrm{LiCl}$. Because there is no apparent sex difference in the acquisition of CTA in experimental rodents (Dalla and Shors, 2009; Pistell et al., 2008), we evaluated CTA with data from male and female animals. There were no differences in the basal level of water or saccharin consumption before CTA between $C d k l 2^{+/+}$and $C d k l 2^{L a c Z / L a c Z}$ mice; water consumption in a day during training days, $C d k l 2^{+/+}$males; $5.19 \pm 0.50 \mathrm{ml}$ vs. $C d k l 2^{\text {LacZ/LacZ }}$ males; $5.09 \pm 0.34 \mathrm{ml}, C d k l 2^{+/+}$females; $4.72 \pm 0.39 \mathrm{ml}$ vs. $C d k l 2^{L a c Z l}$ ${ }^{\text {LacZ }}$ females; $4.96 \pm 0.48 \mathrm{ml}$, saccharin consumption for $20 \mathrm{~min}$ on conditioning day, $C d k l 2^{+/+}$males; $1.03 \pm 0.11 \mathrm{ml}$ vs. $C d k l 2^{\text {LacZ/LacZ }}$ males; $1.22 \pm 0.07 \mathrm{ml}, C d k l 2^{+/+}$females; $0.88 \pm 0.06 \mathrm{ml}$ vs. $C d k l 2^{L a c Z l}$ Lacz females; $0.92 \pm 0.08 \mathrm{ml}$, and water consumption for $24 \mathrm{~h}$ on resting day, $C d k l 2^{+/+}$males; $5.96 \pm 0.35 \mathrm{ml}$ vs. $C d k l 2^{\text {LacZ/LacZ }}$ males;
$4.94 \pm 0.52 \mathrm{ml}, C d k l 2^{+/+}$females; $4.92 \pm 0.32 \mathrm{ml}$ vs. $C d k l 2^{\text {Lacz/LacZ }}$ females; $4.99 \pm 0.64 \mathrm{ml}$ ). CTA was evaluated twice to examine middle-term and long-term memory. CTA-I testing (middle-term memory) was performed 1 day after conditioning and lasted for three consecutive days. CTA-II (long-term memory) was performed 8 days after CTA I for three consecutive days. In CTA-I, both $C d k l 2^{\text {LacZ/LacZ }}(n=10)$ and $C d k l 2^{+/+}(n=10)$ mice injected with $\mathrm{LiCl}$ exhibited a significant aversive response to saccharin (preference score $<0.5)$ compared with $C d k l 2^{\text {LacZ/LacZ }}(n=8)$ and $C d k l 2^{+/+}$ $(n=10)$ mice injected with saline (Figure 8). In CTA-II, the aversive response to saccharin tended to be lower than that of CTA-I in both $C d k l 2^{\text {LacZ/LacZ }}$ and $C d k l 2^{+/+}$mice injected with LiCl. There were no significant differences between genotypes in either CTA-I or CTA-II.

We further attempted to evaluate whether the altered avoidance behavior of $C d k l 2^{\text {LacZ/LacZ }}$ mice observed in the inhibitory avoidance task was accompanied by a change in active avoidance behavior. We used the TAA task with a shuttle box (Archer et al., 1982). The TAA task is considered to measure nondeclarative memory and relies on both classical fear conditioning and instrumental aversive conditioning (Squire, 1992). In this task, the animal has to learn the association between an aversive US and a CS, and learning acquisition is impaired in animals with amygdala lesions or pharmacologic inactivation of amygdala function (Roozendaal et al., 1993; Savonenko et al., 2003; Segura-Torres et al., 2010). The \% 

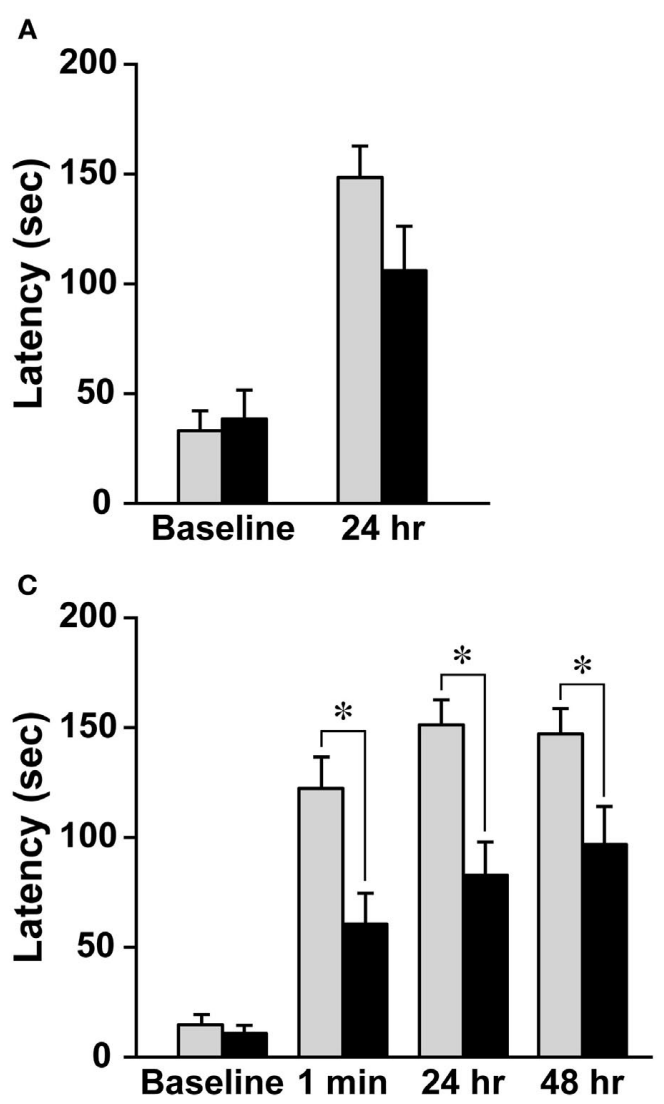
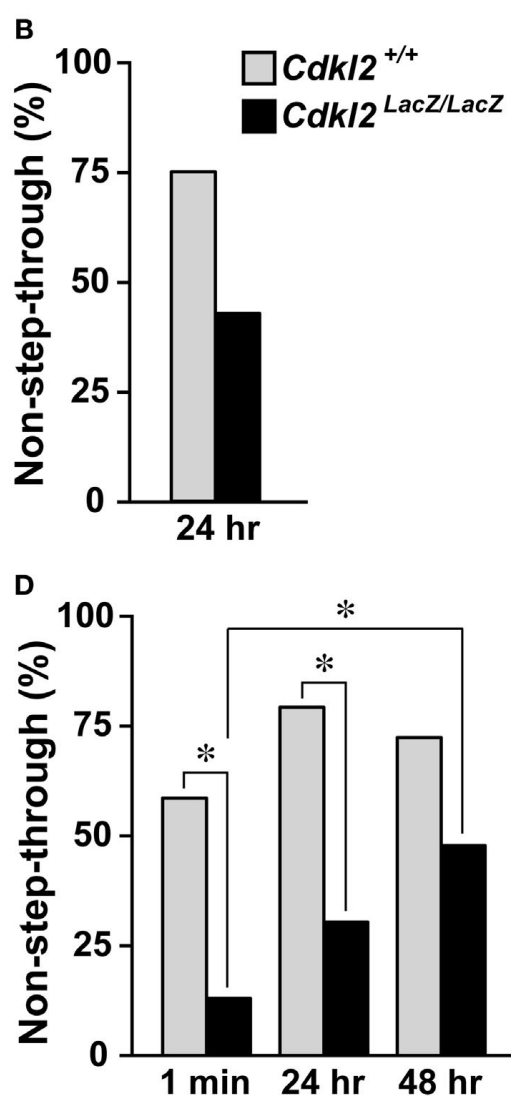

FIGURE 4 | Inhibitory avoidance test. When the animals had stepped with all four paws into the dark compartment, the door was closed and the baseline latency was recorded. The animals were given a single footshock $0.4 \mathrm{~mA}$ for $5 \mathrm{~s})$ and then placed in their home cages. Retention was tested by placing the mice in the lighted compartment and measuring the latency to enter the dark compartment. (A) Step-through latencies to enter the dark compartment were measured $24 \mathrm{~h}$ after footshock. Statistical analysis was performed using the Mann-Whitney U-test. The baseline latencies were not significantly different between genotypes ( $U=102.5, P=0.6926)$. In the 24 -h retention trials, $C d k / 2^{\operatorname{Lac} Z / L a c z}$ mice exhibited reduced latencies, but the difference was not significant $(U=74.0, P=0.0745)$. (B) The percentage of mice that did not enter the dark compartment (non-step-through) in 24-h retention trials was plotted.
A chi-square test revealed that there was no significant difference in percent non-step-through between $C d k / 2^{+/+}$mice and $C d k / 2^{\text {LaczlLacz }}$ mice $\left(\chi^{2}=3.214\right.$, $P=0.0730$ ). (C) Step-through latencies were measured $1 \mathrm{~min}, 24 \mathrm{~h}$, and $48 \mathrm{~h}$ after footshock. The baseline latencies were not significantly different between genotypes $(U=258.5, P=0.1670)$. In the retention trials, $C d k / 2^{\text {Lacz/LacZ }}$ mice exhibited significantly reduced latencies at $1 \mathrm{~min}$ and $24 \mathrm{~h}$ after footshock (1 $\min , U=181.5, P=0.0051,24 \mathrm{~h}, U=163.5, P=0.0017$ and $48 \mathrm{~h}, U=218.5$, $P=0.0341)$. (D) The percentage of non-step-through $C d k / 2^{\text {Laczllacz }}$ mice was significantly different between $1 \mathrm{~min}$ and $24 \mathrm{~h}\left(1 \mathrm{~min}, \chi^{2}=11.258, P=0.0008\right.$ and $\left.24 \mathrm{~h}, \chi^{2}=12.554, P=0.0004\right)$. In Cdk/2 ${ }^{\text {Laczlaac }}$ mice, the percentage of nonstep-through was significantly higher in the 48-h retention test compared to the 1 -min retention test $\left(\chi^{2}=6.571, P=0.0104\right)$.
ARs in first 10 trials of the first day in $C d k l 2^{+/+}$mice $(n=14)$ and Cdkl2 ${ }^{\text {LacZ/LacZ }}$ mice $(n=14)$ was higher $(22 \sim 30 \%)$ than that in second 10 trials $(9 \sim 11 \%)$, presumably due to the fact that the mice were not yet familiar with the shuttle box task and moved randomly in the box (Figure 9A). During the progression of trials, Cdkl2 LacZ/LacZ mice exhibited similar \% ARs to that of $C d k l 2^{+++}$mice. Although there was no significant difference in \% ARs between genotypes, $C d k l 2^{\text {LacZ/LacZ }}$ mice tended to display higher \% ARs during the trials. The differences in AR latency (Figure 9B), crossing responses during the shock (\% ERs), and the ITI (\% non-effective response) were not significantly different between genotypes.

\section{DISCUSSION}

The physiologic role of $\mathrm{Cdkl} 2$ in the adult brain has not yet been elucidated. In the present study, we generated $C d k l 2^{\text {LacZ/ }}$ ${ }^{L a c Z}$ mice to investigate the role of $\mathrm{Cdkl} 2$ in brain function.
$C d k l 2^{\text {LacZ/LacZ }}$ mice were viable and fertile, and exhibited no gross abnormalities in brain anatomy and general behaviors. Analysis of $L a c Z$ localization in adult brain of $C d k l 2^{\text {LacZ/LacZ }}$ mice demonstrated that the strongest expression of $C d k l 2$ was in the cerebral cortex, entorhinal cortex, and hippocampus, suggesting that $\mathrm{Cdkl} 2$ has a potential role in higher brain function. When we analyzed $C d k l 2^{\text {LacZ/LacZ }}$ mice using several behavioral tests, the mutant mice exhibited behavioral abnormalities related to cognitive function in contextual and spatial learning acquisition. Normal nociceptive responses and motor coordination in $C d k l 2^{\text {LacZ/LacZ }}$ mice indicated that these behavioral abnormalities were not caused by sensorimotor deficits. Further, activities in locomotion, exploration, and anxiety-related behavior were not significantly changed in $C d k l 2^{\text {LacZ/LacZ }}$ mice. Here we discuss the behavioral abnormalities in $C d k l 2^{\text {LacZ/LacZ }}$ mice and a potential role of Cdkl2 in brain function. 

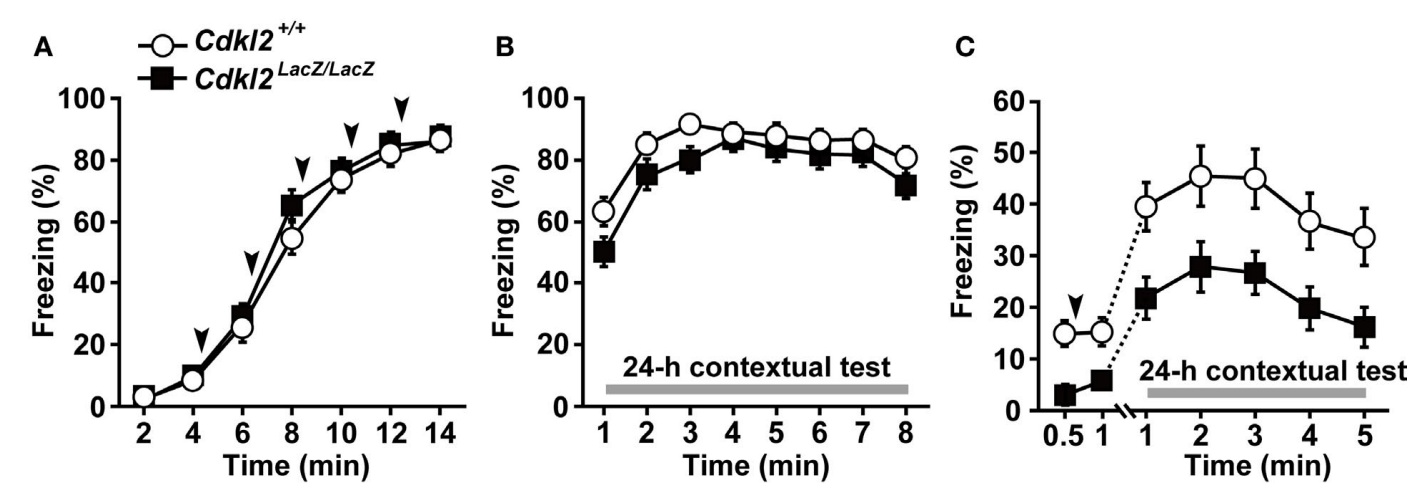

FIGURE 5 | Contextual fear conditioning. Freezing responses were evaluated in two different protocols, (I) and (II). (A) In protocol (I), five footshocks $(0.7 \mathrm{~mA}$ for $1 \mathrm{~s}, 2$ min apart) were given at 4, 6, 8, 10, and 12 min after the animals were placed in the chamber. Pre-shock baseline freezing ( $4 \mathrm{~min}$ ) was not significantly different between $C d k / 2^{+/+}$and $C d k / 2^{\text {LacZlacz }}$ mice. During conditioning, the percent time spent freezing was determined. Arrowheads indicate when the footshock was administered. (B) In the 24-h contextual test, percent time spent freezing was determined for $8 \mathrm{~min}$. Repeated measures ANOVA revealed no significant main effect of genotype on conditioning $\left(F_{(1,28)}=0.034, P=0.8559\right)$ or in the 24-h contextual test $\left(F_{(1,28)}=2.295, P=0.1410\right)$, and there was no significant interaction between genotype and time of conditioning $\left\langle F_{(4,112)}=1.626, P=0.1727\right)$ or in the 24-h contextual test $\left(F_{(7,196)}=1.210\right.$,
$P=0.2991)$. There was a significant difference between $C d k / 2^{+/+}$and $C d k / 2^{\text {LacZlLacz }}$ mice in the mean values in minutes 1,2 , and 3 of the 24-h contextual test $\left(F_{(1,28)}=4.718, P=0.0385\right)$. (C) In protocol (II), a single footshock (0.35 mA for $3 \mathrm{~s})$ was given a $30 \mathrm{~s}$ after the animals were placed in the chamber. Pre-shock baseline freezing (30 s) was significantly decreased in Cdkl2 ${ }^{\text {acz } / L a c Z}$ mice $\left(t_{(38)}=-2.642, P=0.0119\right.$, unpaired Student's $t$-test), but post-shock freezing (30 s) was not significantly different $\left(t_{(38)}=-1.868, P=0.0694\right)$. Percentage of time spent freezing on the 24-h contextual test was measured for $5 \mathrm{~min}$ immediately after the animals were returned to the footshock chamber. Repeated measures ANOVA revealed a significant main effect of genotype $\left(F_{(1,38)}=10.743, P=0.0022\right)$ but the interaction between genotype and time was not significant $\left(F_{(4,152)}=0.003, P>0.9999\right)$.
Table 2 | Measurement of nociceptive responses.

\begin{tabular}{|c|c|c|c|c|}
\hline Genotype & Cdkl2+/+ & Cdk/2 LacZ/LacZ & Cdkl2+/+ & Cdkl2 LacZ/Lacz \\
\hline Sex & \multicolumn{2}{|c|}{ Males } & \multicolumn{2}{|c|}{ Females } \\
\hline Number of animals & 29 & 23 & 15 & 15 \\
\hline \multicolumn{5}{|l|}{ Footshock (mA) } \\
\hline Flinch & 0.10 & 0.10 & 0.10 & 0.11 \\
\hline Vocalization & 0.18 & 0.20 & 0.16 & 0.17 \\
\hline Jump & 0.37 & 0.36 & 0.38 & 0.40 \\
\hline Hot-plate (s) & 22.4 & 19.8 & 31.9 & 31.8 \\
\hline
\end{tabular}

Data are expressed as the mean value.

In the inhibitory avoidance task, $C d k l 2^{\text {LacZ/LacZ }}$ mice had reduced latencies to enter the dark chamber in the retention tests. The percentages of mice that did not enter the dark compartment was also lower in $C d k l 2^{\text {LacZ/LacZ }}$ mice. Although the reduced latency in $C d k l 2^{\text {LacZ/LacZ }}$ mice measured in a single 24 -h retention test was not significantly different compared to that in $C d k l 2^{+/+}$mice, strong and significant avoidance activities were observed when $C d k l 2^{\text {LacZ/ }}$ ${ }_{\text {LacZ }}$ mice were tested with a shorter retention time $(1 \mathrm{~min})$ after footshock. The avoidance activities persisted for up to the 48-h retention test, but gradually weakened over time. These results suggest that $\mathrm{Cdkl} 2$ plays a role in consolidation of fear memory. Studies of brain lesions and pharmacologic inactivation support the notion that an initial memory is formed in the amygdala and is necessary for subsequent storage elsewhere in the learning of inhibitory avoidance (Liang et al., 1982, 1994; Kim and McGaugh, 1992; Parent et al., 1992). In addition to the amygdala, the hippocampus and other regions, such as the entorhinal cortex, parietal cortex, and medial septal area, are involved in this task, suggesting that the sequential and anatomic connectivity of the neural circuit is important in this type of learning (Izquierdo et al., 1992, 1997; Ambrogi Lorenzini et al., 1996, 1997, 1999). Thus, impaired inhibitory avoidance in $C d k l 2^{\text {LacZ/LacZ }}$ mice may be due to dysfunction of the linking pathways, including those between the amygdala, hippocampus, entorhinal cortex, and cerebral cortex.

We used two protocols for the contextual fear conditioning, with either strong or mild conditioning stimuli. $C d k l 2^{\text {LacZ/LacZ }}$ mice displayed a significant but subtle impairment in freezing response $24 \mathrm{~h}$ after repeated presentation of the US with a longer CS duration (Figure 5B). Interestingly, if mice that were pre-exposed to the inhibitory avoidance test (Figures 4C,D) were given a short CS and single US pair, they exhibited a more significant decrease in 24-h context-dependent freezing (Figure 5C). In the later case, $C d k l 2^{\text {LacZ/LacZ }}$ mice had a lower freezing baseline in the pre-shock period. Nevertheless, the results of contextual fear conditioning suggest that $C d k l 2^{\text {LacZ/LacZ }}$ mice had impaired freezing behavior accompanied by a mild learning deficit and the degree of disability seems to be dependent on the stimulus threshold for conditioning and/or prior experience. Several lines of evidence suggest that the amygdala and hippocampus constitute major substrates of the neural circuit required for contextual fear conditioning (Selden et al., 1991; Kim and Fanselow, 1992; Phillips and LeDoux, 1992; Kim et al., 1993; Maren and Fanselow, 1997; Anagnostaras et al., 1999). Although context-dependent fear conditioning is widely accepted as a hippocampus-dependent learning task, a recent review points out that there is no absolute requirement for the hippocampus in fear conditioning to context and that nonassociative factors may influence fear response behavior (Maren, 2008). Therefore, it is difficult to declare which neural structure is critically related to the deficit in contextual fear conditioning in Cdkl2 ${ }^{\text {LacZ/LacZ }}$ mice. 

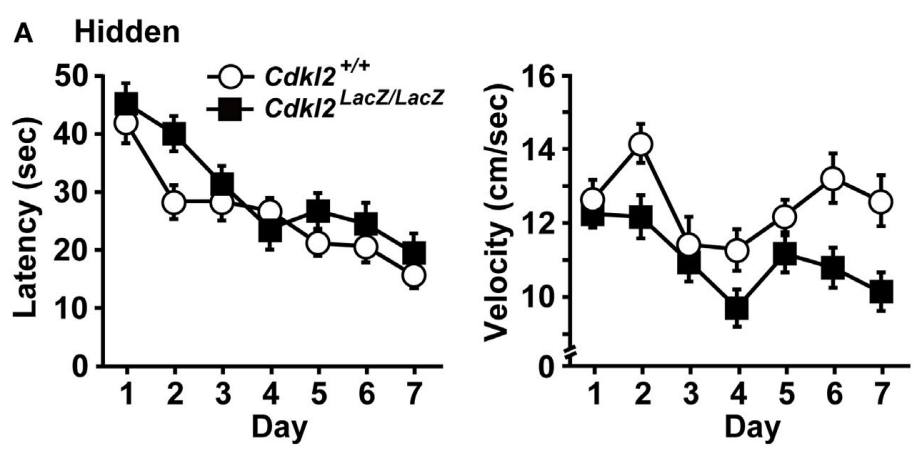

B Probe test
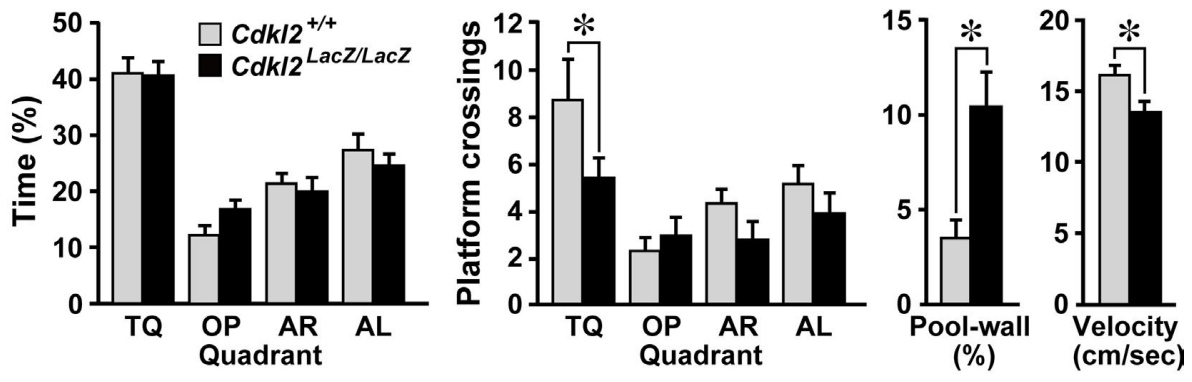

\section{Visible}
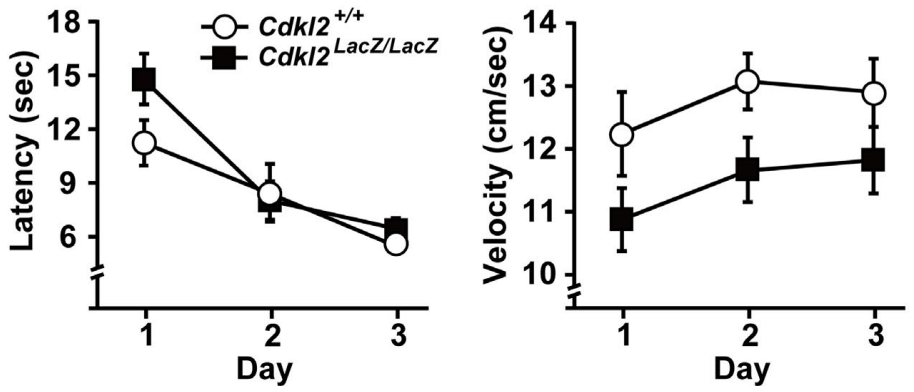

FIGURE 6 | Morris water maze (MWM). (A) The escape latency (left) and swimming velocity (right) in each session of the hidden-platform test. There was a significant main effect in escape latency among trial sessions based on repeated measures ANOVA $\left(F_{(6,162)}=20.731, P<0.001\right)$, but the main effect between genotypes was not significant $\left(F_{(1,27)}=2.465, P=0.1281\right)$. There was a significant main effect between genotypes in the swimming velocity $\left(F_{(1,27)}=7.351, P=0.0115\right)$. (B) Swimming profiles in the probe test. The percent quadrant search time (left), number of crossings over the platform position in the target quadrant (middle), percent time swimming along the pool-wall, and swimming velocity (right) were analyzed. Cdk/2 ${ }^{\text {acz/LacZ }}$ mice crossed the platform position significantly less often than $C d k / 2^{+/+}$mice. Significant main effects were detected among quadrants by ANOVA $\left(F_{(3,81)}=8.462, P<0.0001\right)$ and between genotypes $\left(F_{(1,27)}=4.197, P=0.0500\right)$. Significant differences in the percentage of the time swimming along the pool wall $\left(t_{(27)}=3.379\right.$, $P=0.0022)$ and swimming velocity $\left(t_{(27)}=-3.068, P=0.0049\right)$ were detected between genotypes by unpaired Student's $t$-test. (C) The escape latency (left) and swimming velocity (right) in each session of the visible-platform test. A significant main effect among trial sessions was detected by repeated measures ANOVA $\left(F_{(2,54)}=31.254, P<0.0001\right)$, but there was no main effect between genotypes $\left(F_{(1,27)}=1.217, P=0.2797\right)$. A significant main effect between genotypes was detected in the swimming velocity $\left(F_{(1,27)}=4.607\right.$, $P=0.0410)$.

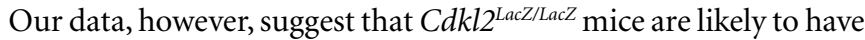
impaired hippocampal function rather than impaired amygdaloid function. The fact that the $C d k l 2^{\text {LacZ/LacZ }}$ mice were not impaired in CTA, an amygdala-dependent learning task, is consistent with this idea. In CTA, Cdkl2 ${ }^{\text {LacZ/LacZ }}$ mice learned to associate a saccharin taste and visceral malaise induced by $\mathrm{LiCl}$. In the retention of aversive memory, $C d k l 2^{\text {LacZ/LacZ }}$ mice showed a similar term-dependency to that of $C d k l 2^{+/+}$mice. Consistently, there was no significant difference in the TAA task between genotypes. Early and recent studies demonstrate that acquisition of TAA is impaired in animals with amygdala lesions and pharmacologic inactivation of NMDA receptors in the amygdala (Roozendaal et al., 1993; Savonenko et al.,

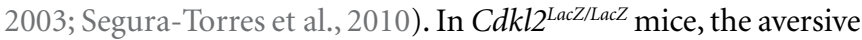
response in TAA was slightly, but not significantly, enhanced. Regarding the enhanced aversive response in Cdkl2 ${ }^{\text {LacZ/LacZ }}$ mice, it is notable that lesions of the hippocampus and related structures such as the fimbria-fornix and tuberomammilary nucleus improve or facilitate the acquisition of TAA (Gray and McNaughton, 1983; Segura-Torres et al., 1996; Weiner et al., 1998; Guillazo-Blanch et al., 2002). Therefore, the overall pattern of behavioral abnormalities of $C d k l 2^{\text {LacZ/LacZ }}$ mice in context-dependent behavioral paradigms suggests that the contribution of amygdala impairment is not as large as that of impairment of the hippocampus and hippocampal-related regions. 


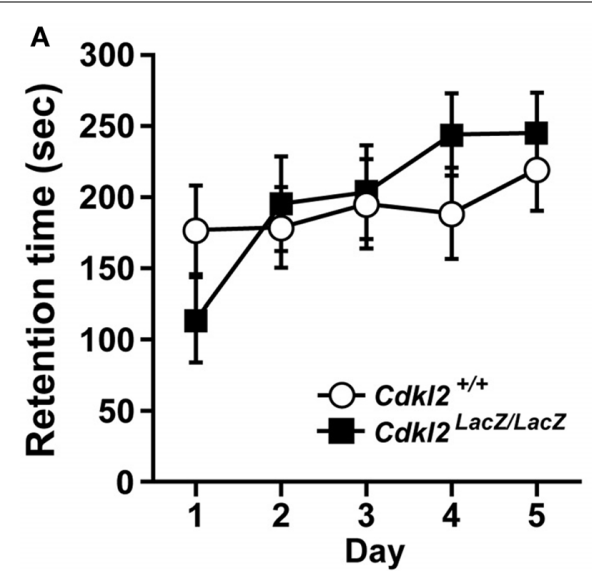

FIGURE 7 | Rotating-rod test. (A) Mice were trained once a day for five consecutive days. Maximal time allowed on the rotating-rod was $300 \mathrm{~s}$. (B) Mice were repeatedly trained for 1 day until they stayed on the rod longer than $60 \mathrm{~s}$.

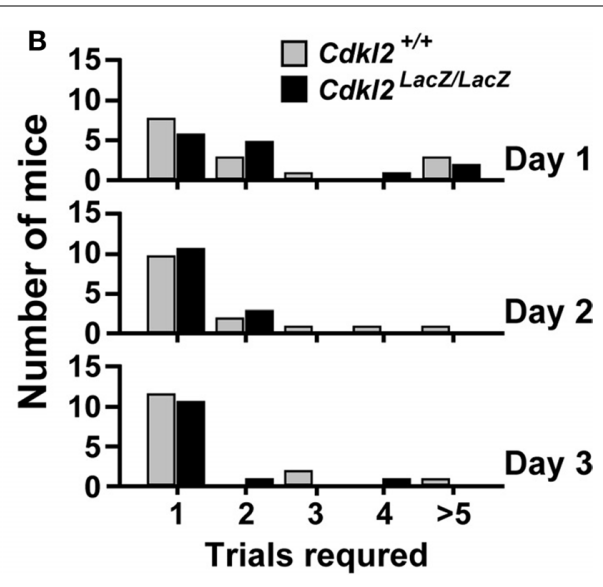

The training was performed for three consecutive days. There were no significant differences between $C d k / 2^{+/+}$and $C d k / 2^{\text {LacZllacz }}$ mice in either type of test (Mann-Whitney U-test).
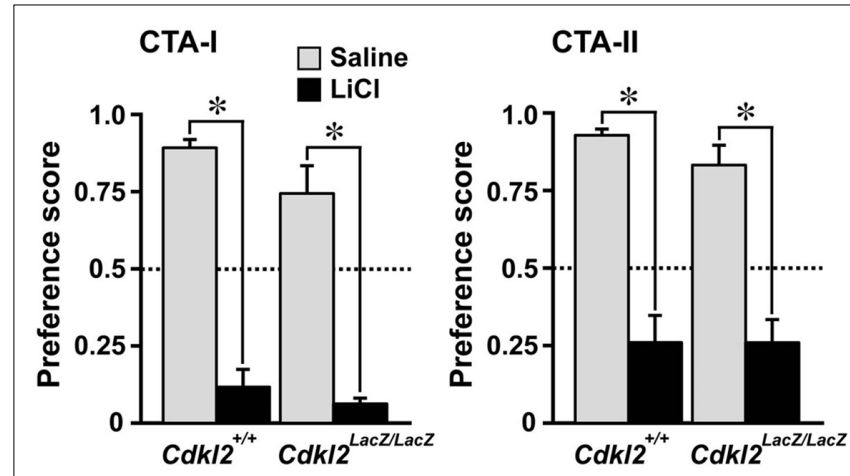

FIGURE 8 | Conditioned taste aversion (CTA). The data are expressed as relative ratios of the saccharin consumption/water and saccharin consumption (preference score) for each mouse using the two-bottle choice procedure. Preference score is the mean of three consecutive days of measurements. $\mathrm{Cd} / 2^{+/+}$and $\mathrm{Cd} / 2^{\mathrm{Lacz} / \mathrm{LaCZ}}$ mice significantly learned equally well to avoid saccharin following saccharin-lithium chloride paired conditioning in both CTA-I and $-I$ ( $P<0.0015$, Mann-Whitney $U$-test). The data were collected from $C d k / 2^{+/+}$(four males and six females) and $C d k 12^{\operatorname{Lac} Z / L a c Z}$ (three males and five females) mice injected with saline, and from Cdk/2 ${ }^{+/+}$(four males and six

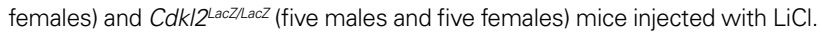

In the MWM, we observed a curious behavioral feature in $C d k l 2^{\text {LacZ/LacZ }}$ mice. Cdkl2 ${ }^{\text {LacZ/LacZ }}$ mice had slightly impaired spatial learning as well as some deficits in emotion, motivation, and swimming activity. While $C d k l 2^{\text {LacZ/LacZ }}$ mice exhibited a significant decrease in the escape latency required to find the platform location in the hidden-platform version and increased time spent in the trained quadrant in the probe test, they exhibited significantly fewer platform crossings in the probe test. In the MWM task, increased time spent in the trained quadrant and crossing frequency of platform position in the probe test as well as decreased escape latency in the hidden-platform version are considered to be indicators of spatial memory (Morris et al., 1982; Silva et al., 1992). Therefore, it is unlikely that $C d k l 2^{\mathrm{LacZ} / \mathrm{LacZ}}$ mice have severely impaired spatial memory per se, but they presumably have a deficit in fine-tuning of the precise location of the platform. $C d k l 2^{L a c z / L a c Z}$ mice spent a higher percentage of time swimming along the pool-wall with a slower swimming velocity, despite their normal motor and visual function. This phenotypic feature in $C d k l 2^{\text {LacZ/LacZ }}$ mice is probably due to an alteration in cognitive function. For example, while $C d k l 2^{+/+}$mice develop a strategy for finding the platform by swimming quickly but stopping periodically to reassess their strategy, $C d k l 2^{\text {LacZ/LacZ }}$ mice utilize a strategy in which they swim slowly but continuously. The ability to conduct sustained action or decisionmaking based on cognitive assessment of the current situation might be impaired in $C d k l 2^{\text {LacZ/LacZ }}$ mice. In relation to this point, subtle changes in other behaviors of $C d k l 2^{\text {LacZ/LacZ }}$ mice should not be overlooked. $C d k l 2^{L a c Z / L a c Z}$ mice displayed a high avoidance tendency in TAA, high frequency of rearings in the open field, and increased total distance traveled in the elevated plus-maze. Therefore, we cannot rule out the possibility that a slight emotional impairment produces the behavioral phenotype of $C d k l 2^{L a c Z / L a c Z}$ mice in the MWM. Further electrophysiologic study using hippocampal slices will help to evaluate the hippocampal function and explain the behavioral abnormalities of $C d k l 2^{\text {LacZ/LacZ }}$ mice with respect to synaptic plasticity.

Although the function of Cdkl kinases in vivo is unclear, recent discoveries that mutations of human CDKL3 (Dubos et al., 2008) and CDKL5 can cause mild IDD and X-linked Rett syndrome (Kalscheuer et al., 2003; Tao et al., 2004; Weaving et al., 2004), respectively, suggest possible roles of the Cdkl family in neurodevelopmental or neuropsychiatric function. At least 10 mutations in CDKL5 have been identified in girls with an atypical form of Rett syndrome known as the early-onset seizure variant (Nemos et al., 2009). This severe form of the disorder includes many of the features of classic Rett syndrome (caused by gene mutation of methylCpG-binding protein 2), including developmental disability, loss of language skills, and repeated hand wringing or hand washing movements as well as recurrent seizures. Children with this condition also have profound intellectual disability. Inactivation of human CDKL3 caused by a balanced reciprocal translocation between chromosome $\mathrm{X}$ and $5[46, \mathrm{X}, \mathrm{t}(\mathrm{X} ; 5)(\mathrm{p} 11.1 ; \mathrm{q} 31.1)]$ is associated with nonspecific 

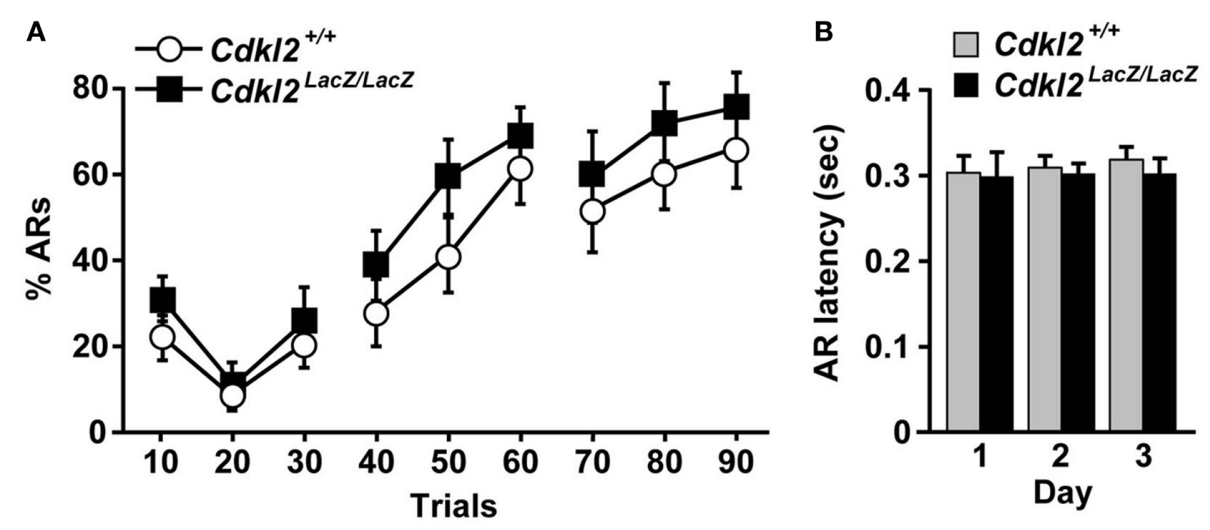

FIGURE 9 |Two-way active avoidance (TAA). (A) Percent avoidance response (\% ARs) over 3 days (30 trials/day) is plotted. Repeated measures ANOVA revealed no significant main effect of genotype $\left(F_{(1,26)}=1.176, P=0.2881\right)$ and no significant interaction between genotype and day $\left(F_{(8,208)}=0.292\right.$, $P=0.9680$ ). (B) AR latency by trial days. Unpaired Student's $t$-test revealed no significant differences between $\mathrm{Cdk} / 2^{+/+}$and $\mathrm{Cdkl} 2^{\mathrm{LacZ} Z \mathrm{LacZ}}$ mice. mild IDD (Dubos et al., 2008). The expression of Cdkl5 in mice is strongly induced in early postnatal stages, and in the adult brain Cdkl5 is present in mature neurons, but not in astrocytes (Rusconi et al., 2008). The carboxy-terminal tail regulates the subcellular localization of Cdkl5, which undergoes nucleocytoplasmic shuttling. A similar developmental expression pattern in the brain and subcellular localization in neurons are observed for Cdkl2. Thus, some overlapping or similar potential relevance of these molecules might be involved in their functions.

In summary, $\mathrm{Cdkl} 2$ appears to be involved in normal behavioral control relating to the cognitive function required to acquire contextual and spatial learning in mice. Our results provide new insight into the in vivo function of neuronal Cdkl kinases in mice. Searching for the biochemical substrates and interacting proteins of $\mathrm{Cdkl} 2$ and development of a circuit-specific conditional knockout mice

\section{REFERENCES}

Anagnostaras, S. G., Maren, S., and Fanselow, M. S. (1999). Temporally graded retrograde amnesia of contextual fear after hippocampal damage in rats, within-subjects examination. $J$. Neurosci. 19, 1106-1114.

Ambrogi Lorenzini, C. G., Baldi, E., Bucherelli, C., Sacchetti, B., and Tassoni, G. (1996). Role of dorsal hippocampus in acquisition, consolidation and retrieval of rat's inhibitory avoidance response, a tetrodotoxin functional inactivation study. Brain Res. 730, 32-39.

Ambrogi Lorenzini, C. G., Baldi, E., Bucherelli, C., Sacchetti, B., and Tassoni, G. (1997). Role of ventral hippocampus in acquisition, consolidation and retrieval of rat's inhibitory avoidance response memory trace. Brain Res. 768, 242-248.

Ambrogi Lorenzini, C. G., Baldi, E., Bucherelli,C., Sacchetti, B., and Tassoni, G. (1999). Neural topography and chronology of memory consolidation, a review of functional inactivation findings. Neurobiol. Learn. Mem. 71, 1-18. Archer, T., Ogren, S. O., Johansson, G., and Ross, S. B. (1982). DSP4-induced two-way active avoidance impairment in rats, involvement of central and not peripheral noradrenaline depletion. Psychopharmacology (Berl.) 76, 303-309.

Atkins, C. M., Selcher, J. C., Petraitis, J. J., Trzaskos, J. M., and Sweatt, J. D. (1998). The MAPK cascade is required for mammalian associative learning. Nat. Neurosci. 1, 602-609.

Dalla, C., and Shors, T. J. (2009). Sex differences in learning processes of classical and operant conditioning. Physiol. Behav. 97, 229-238.

Deisseroth, K., Bito, H., and Tsien, R. W. (1996). Signaling from synapse to nucleus: postsynaptic CREB phosphorylation during multiple forms of hippocampal synaptic plasticity. Neuron 16, 89-101.

will contribute to elucidating the detailed molecular mechanisms of Cdkl2 function and the critical neural circuit involving by Cdkl2 in learning.

\section{ACKNOWLEDGMENTS}

We wish to thank Ms. Yumi Onodera for her excellent technical assistance with the behavioral experiments. Hiroshi Gomi wishes to thank Dr. Yasunobu Yasoshima for advice regarding the CTA experiment. Takayuki Sassa wishes to thank Prof. Koreaki Ito for his continuous encouragement. This work was supported in part by a RIKEN BSI research grant, a Grant-in-Aid for Scientific Research on Priority Area-Molecular Brain Science-from the Ministry of Education, Science, Sports, and Culture of Japan (Shigeyoshi Itohara), and a Grant-in-Aid for Scientific Research from the Ministry of Education, Science, Sports, and Culture of Japan (Hiroshi Gomi).

Dubos, A., Pannetier, S., and Hanauer, A. (2008). Inactivation of the CDKL3 gene at $5 \mathrm{q} 31.1$ by a balanced $t(X ; 5)$ translocation associated with nonspecific mild mental retardation. Am. J. Med. Genet. A 146A, 1267-1279.

Gomi, H., Sun, W., Finch, C. E., Itohara, S., Yoshimi, K., and Thompson, R. F. (1999). Learning induces a CDC2related protein kinase, KKIAMRE. J. Neurosci. 19, 9530-9537.

Grana, X., Claudio, P.P., De Luca, A., Sang, N., and Giordano, A. (1994). PISSLRE, a human novel CDC2-related protein kinase. Oncogene 9, 2097-2103.

Gray, J. A., and McNaughton, N. (1983). Comparison between the behavioural effects of septal and hippocampal lesions: a review. Neurosci. Biobehav. Rev. 7, 119-188.

Guillazo-Blanch, G., Nadal, R., ValeMartínez, A., Martí-Nicolovius, M., Arévalo, R., and Morgado-Bernal, I. (2002). Effects of fimbria lesion on trace two-way active avoidance acquisition and retention in rats. Neurobiol. Learn. Mem. 78, 406-425.

Haq, R, Randall, S., Midmer, M., Yee, K., and Zanke, B. (2001). NKIATRE is a novel conserved cdc2-related kinase. Genomics 71, 131-141.

Hawasli, A. H., Benavides, D. R., Nguyen, C., Kansy, J. W., Hayashi, K., Chambon, P., Greengard, P., Powell, C. M., Cooper, D. C., and Bibb, J. A. (2007). Cyclindependent kinase 5 governs learning and synaptic plasticity via control of NMDAR degradation. Nat. Neurosci. 10, 880-886.

Hawasli, A. H., Koovakkattu, D., Hayashi, K., Anderson, A. E., Powell, C. M., Sinton, C. M., Bibb, J. A., and Cooper, D. C. (2009). Regulation of hippocampal and behavioral excitability by cyclin-dependent kinase 5 . PLoS ONE 4, e5808. doi:10.1371/journal. pone.0005808.

Hirose, T., Tamaru, T., Okumura, N., Nagai, K., and Okada, M. (1997). PCTAIRE 2, a Cdc2-related serine/ 
threonine kinase, is predominantly expressed in terminally differentiated neurons. Eur. J. Biochem. 249, 481-488.

Izquierdo, I., da Cunha, C., Rosat, R., Jerusalinsky, D., Ferreira, M. B., and Medina,J.H.(1992). Neurotransmitter receptors involved in post-training memory processing by the amygdala, medial septum, and hippocampus of the rat. Behav. Neural Biol. 58, 16-26.

Izquierdo, I., Quillfeldt, J. A., Zanatta, M. S., Quevedo, J., Schaeffer, E., Schmitz, P. K., and Medina, J. H. (1997). Sequential role of hippocampus and amygdala, entorhinal cortex and parietal cortex in formation and retrieval of memory for inhibitory avoidance in rats. Eur. J. Neurosci. 9, 786-793.

Kalscheuer, V. M., Tao, J., Donnelly, A., Hollway, G., Schwinger, E., Kubart, S., Menzel, C., Hoeltzenbein, M., Tommerup, N., Eyre, H., Harbord, M., Haan, E., Sutherland, G. R., Ropers, H.-H., and Gécz, J. (2003). Disruption of the serine/threonine kinase 9 gene causes severe $\mathrm{X}$-linked infantile spasms and mental retardation. Am. J. Hum. Genet. 72, 1401-1411.

Kameshita, I., Sekiguchi, M., Hamasaki, D., Sugiyama, Y., Hatano, N., Suetake, I., Tajima, S., and Sueyoshi, N. (2008). Cyclin-dependent kinase-like 5 binds and phosphorylates DNA methyltransferase 1. Biochem. Biophys. Res. Commun. 377, 1162-1167.

Kim, J. J., DeCola, J. P., LandeiraFernandez, J., and Fanselow, M. S. (1991). N-methyl-D-aspartate receptor antagonist APV blocks acquisition but not expression of fear conditioning. Behav. Neurosci. 105, 126-133.

Kim, J. J., and Fanselow, M. S. (1992). Modality-specific retrograde amnesia of fear. Science 256, 675-677.

Kim, M., and McGaugh, J. L. (1992). Effects of intra-amygdala injections of NMDA receptor antagonists on acquisition and retention of inhibitory avoidance. Brain Res. 585, 35-48.

Kim, J. J., Rison, R. A., and Fanselow, M. S. (1993). Effects of amygdala, hippocampus and periaqueductal gray lesions on short- and long-term contextual fear. Behav. Neurosci. 107, 1093-1098.

Lazzaro, M. A., Albert, P. R., and Julien, J. P. (1997). A novel cdc2-related protein kinase expressed in the nervous system. J. Neurochem. 69, 348-364.

LeBouffant, F., Le Minter, P., Traiffort, E., Ruat, M., and Sladeczek, F. (2000). Multiple subcellular localizations of PCTAIRE-1 in brain. Mol. Cell. Neurosci. 16, 388-395.

Lee, H.-K. (2006). Synaptic plasticity and phosphorylation. Pharmacol. Ther. 112, 810-832.
Liang, K. C., Hon, W., and Davis, M. (1994). Pre- and posttraining infusion of N-methyl-D-aspartate receptor antagonists into the amygdala impair memory in an inhibitory avoidance task. Behav. Neurosci. 108, 241-253.

Liang, K. C., McGaugh, J. L., Martinez, J. L. Jr., Jensen, R. A., Vasquez, B. J., and Messing, R. B. (1982). Post-training amygdaloid lesions impair retention of an inhibitory avoidance response. Behav. Brain Res. 4, 237-249.

Lister, R. G. (1987). The use of a plusmaze to measure anxiety in the mouse. Psychopharmacology (Berl.) 92, 180-185.

Lorenzini, C. A., Baldi, E., Bucherelli, C., Sacchetti, B., and Tassoni, G. (1996). Role of dorsal hippocampus in acquisition, consolidation and retrieval of rat's inhibitory avoidance response, a tetrodotoxin functional inactivation study. Brain Res. 730, 32-39.

Malumbres, M., Harlow, E., Hunt, T., Hunter, T., Lahti, J. M., Manning, G., Morgan, D. O., Tsai, L.-H., and Wolgemuth, D. J. (2009). Cyclindependent kinases: a family portrait. Nat. Cell Biol. 11, 1275-1276.

Maren, S. (2008). Pavlovian fear conditioning as a behavioral assay for hippocampus and amygdala function: cautions and caveats. Eur. J. Neursci. 28, 1661-1666.

Maren, S., and Fanselow, M. S. (1997). Electrolytic lesions of the fimbria/fornix, dorsal hippocampus, or entorhinal cortex produce anterograde deficits in contextual fear conditioning in rats. Neurobiol. Learn. Mem. 67, 142-149.

Mari, F., Azimonti, S., Bertani, I., Bolognese, F., Colombo, E., Caselli, R., Scala, E., Longo, I., Grosso, S., Pescucci, C., Ariani, F., Hayek, G., Balestri, P., Bergo, A., Badaracco, G., Zappella, M., Broccoli, V., Renieri, A., Kilstrup-Nielsen, C., and Landsberger, N. (2005). CDKL5 belongs to the same molecular pathway of $\mathrm{MeCP} 2$ and it is responsible for the early-onset seizure variant of Rett syndrome. Hum. Mol. Genet. 14, 1935-1946.

Martin, K. C., Michael, D., Rose, J. C., Barad, M., Casadio, A., Zhu, H., and Kandel, E. R. (1997). MAP kinase translocates into the nucleus of the presynaptic cell and is required for long-term facilitation in Aplysia. Neuron 18, 899-912.

Midmer, M., Haq, R., Squire, J. A., and Zanke, B. W. (1999). Identification of NKIAMRE, the human homologue to the mitogen-activated protein kinase-/cyclin-dependent kinaserelated protein kinase NKIATRE, and its loss in leukemic blasts with chromosome arm $5 q$ deletion. Cancer Res. 59, 4069-4074.
Morgan, D. O. (1995). Principles of CDK regulation. Nature 374, 131-134.

Morris, R. G., Garrud, P., Rawlins, J. N. and O'Keefe, J. (1982). Place navigation impaired in rats with hippocampal lesions. Nature 297, 681-683.

Nachman, M., and Ashe, J. H. (1974) Effects of basolateral amygdala lesions on neophobia, learned taste aversions, and sodium appetite in rats. J. Comp. Physiol. Psychol. 87, 622-643.

Nemos, C., Lambert, L., Giuliano, F., Doray, B., Roubertie, A., Goldenberg, A., Delobel, B., Layet, V., N'guyen, M. A., Saunier, A., Verneau, F., Jonveaux, P., and Philippe, C. (2009). Mutational spectrum of CDKL5 in early-onset encephalopathies: a study of a large collection of French patients and review of the literature. Clin. Genet. 76, 357-371.

Ohshima, T., Ward, J. M., Huh, C. G. Longenecker, G., Veeranna, Pant, H. C., Brady, R. O., Martin, L. J., and Kulkarni, A. B. (1996). Targeted disruption of the cyclin-dependent kinase 5 gene results in abnormal corticogenesis, neuronal pathology and perinatal death. Proc. Natl. Acad. Sci. U.S.A. 93, 11173-11178.

Parent, M. B., Tomaz, C., and McGaugh, J. L. (1992). Increased training in an aversively motivated task attenuates the memory-impairing effects of posttraining N-methyl-D-aspartateinduced amygdala lesions. Behav. Neurosci. 106, 789-797.

Phillips, R. G., and LeDoux, J. E. (1992). Differential contribution of amygdala and hippocampus to cued and contextual fear conditioning. Behav. Neurosci. 106, 274-285.

Pistell, P. J., Zhu, M., and Ingram, D. K. (2008). Acquisition of conditioned taste aversion is impaired in the amyloid precursor protein/presenilin 1 mouse model of Alzheimer's disease. Neuroscience 152, 594-600.

Roozendaal, B., Koolhaas, J. M., and Bohus, B. (1993). The central amygdala is involved in conditioning but not in retention of active and passive shock avoidance in male rats. Behav. Neural Biol. 59, 143-149.

Rusconi, L., Salvatoni, L., Giudici, L., Bertani, I., Kilstrup-Nielsen, C., Vania Broccoli, V., and Landsberger, N. (2008). CDKL5 expression is modulated during neuronal development and its subcellular distribution is tightly regulated by the C-terminal tail. J. Biol. Chem. 283, 30101-30111.

Sassa, T., Gomi, H., and Itohara, S. (2004). Postnatal expression of $\mathrm{Cdkl} 2$ in mouse brain revealed by LacZ inserted into the Cdkl2 locus. Cell Tissue Res. 315, 147-156.
Sassa, T., Gomi, H., Sun, W., Ikeda, T., Thompson, R. F., and Itohara, S. (2000). Identification of variants and dual promoters of murine serine/threonine kinase KKIAMRE. J. Neurochem. 74, 1809-1819.

Satoh, Y., Endo, S., Ikeda, T., Yamada, K., Ito, M., Kuroki, M., Hiramoto, T., Imamura, O., Kobayashi, Y., Watanabe, Y., Itohara, S., and Takishima, K. (2007). Extracellular signal-regulated kinase 2 (ERK2) knockdown mice show deficits in long-term memory; ERK2 has a specific function in learning and memory. J. Neurosci. 27, 10765-10776.

Savonenko, A., Werka, T., Nikolaev, E., Zieliñski, K., and Kaczmarek, L. (2003). Complex effects of NMDA receptor antagonist $\mathrm{APV}$ in the basolateral amygdala on acquisition of two-way avoidance reaction and long-term fear memory. Learn. Mem. 10, 293-303.

Segura-Torres, P., Wagner, U., MassanesRotger, E., Aldavert-Vera, L., MartíNicolovius, M., and Morgado-Bernal, I. (1996). Tuberomammillary nucleus lesion facilitates two-way active avoidance in rats. Behav. Brain Res. 82, 113-117.

Segura-Torres, P., Aldavert-Vera, L., Gatell-Segura,A., and Redolar-Ripoll, D. (2010). Intracranial self-stimulation recovers learning and memory capacity in basolateral amygdala-damaged rats. Neurobiol. Learn. Mem. 93, 117-126.

Selcher, J. C., Atkins, C. M., Trzaskos, J. M., Paylor, R., and Sweatt, J. D. (1999). A necessity for MAP kinase activation in mammalian spatial learning. Learn. Mem. 6, 478-490.

Selcher, J. C., Weeber, E. J., Christian, J., Nekrasova, T., Landreth, G. E., and Sweatt, J. D. (2003). A role for ERK MAP kinase in physiologic temporal integration in hippocampal area CA1. Learn. Mem. 10, 26-39.

Selden, N. R., Everitt, B. J., Jarrard, L. E., and Robbins, T. W. (1991). Complementary roles for the amygdala and hippocampus in aversive conditioning to explicit and contextual cues. Neuroscience 42, 335-350.

Shibuki, K., Gomi, H., Chen, L., Bao, S., Kim, J. J., Wakatsuki, H., Fujisaki, T., Fujimoto, K., Katoh, A., Ikeda, T., Chen, C., Thompson, R. F., and Itohara, S. (1996). Deficient cerebellar long-term depression, impaired eyeblink conditioning, and normal motor coordination in GFAP mutant mice. Neuron 16, 587-599.

Silva, A. J., Kogan, J. H., Frankland, P. W., and Kida, S. (1998). CREB and memory. Annu. Rev. Neurosci. 21, 127-148. 
Silva, A. J., Paylor, R., Wehner, J. M., and Tonegawa, S. (1992). Impaired spatial learning in alpha-calcium-calmodulin kinase II mutant mice. Science 257, 206-211.

Squire, L. R. (1992). Memory and the hippocampus - a synthesis from findings with rats, monkeys, and humans. Psychol. Rev. 99, 1837-1893.

Taglienti, C. A., Wysk, M., and Davis, R. J. (1996). Molecular cloning of the epidermal growth factor-stimulated protein kinase p56 KKIAMRE. Oncogene 13, 2563-2574.

Tao, J., Van Esch, H., Hagedorn-Greiwe, M., Hoffmann, K., Moser, B., Raynaud, M., Sperner, J., Fryns, J.-P., Schwinger, E., Gécz, J., Ropers, H.-H., and Kalscheuer, V. M. (2004). Mutations in the X-linked cyclin-dependent kinase-like 5 (CDKL5/STK9) gene are associated with severe neurodevelopmental retardation. Am. J. Hum. Genet. 75, 1149-1154.
Tsai, L. H., Takahashi, T., Caviness, V. S. Jr., and Harlow, E. (1993). Activity and expression pattern of cyclindependent kinase 5 in the embryonic mouse nervous system. Development 119, 1029-1040.

Weaving, L. S., Christodoulou, J., Williamson, S. L., Kathie L. Friend, K. L., McKenzie, O. L. D., Archer, H., Evans, J., Clarke, A., Pelka, G. J., Tam, P. P. L., Watson, C., Lahooti, H., Ellaway, C. J., Bennetts, B., Leonard, H., and Gécz, J. (2004). Mutations of CDKL5 cause a severe neurodevelopmental disorder with infantile spasms and mental retardation. Am. J. Hum. Genet. 75, 1079-1093.

Weiner, I., Feldon, J., Tarrasch, R., Hairston, I., and Joel, D. (1998). Fimbria-fornix cut affects spontaneous activity, two-way avoidance and delayed non matching to sample, but not latent inhibition. Behav. Brain Res. 96, 59-70.
Yamamoto, T., and Fujimoto, Y. (1991). Brain mechanisms of taste aversion learning in the rats. Brain Res. Bull. 27, 403-406.

Yamamoto, T., Shimura, T., Sako, N., Yasoshima, Y., and Sakai, N. (1994). Neural substrates for conditioned taste aversion in the rat. Behav. Brain Res. 65, 123-137.

Yee, K. W., Moore, S. D., Midmer, M., Zanke, B. W., Tong, F., Hedley, D., and Minden, M. D. (2003). NKIAMRE, a novel conserved CDC2-related kinase with features of both mitogen-activated protein kinases and cyclin-dependent kinases. Biochem. Biophys. Res. Commun. 308, 784-792.

Yen, S. H., Kenessey, A., Lee, S. C., and Dickson, D. W. (1995). The distribution and biochemical properties of a Cdc2-related kinase, KKIALRE, in normal and Alzheimer brains. J. Neurochem. 65, 2577-2584.
Conflict of Interest Statement: The authors declare that the research was conducted in the absence of any commercial or financial relationships that could be construed as a potential conflict of interest.

Received: 30 December 2009; paper pending published: 25 January 2010; accepted: 29 March 2010; published online: 19 April 2010.

Citation: Gomi H, Sassa T, Thompson $R F$ and Itohara $S$ (2010) Involvement of cyclin-dependent kinase-like 2 in cognitive function required for contextual and spatial learning in mice. Front. Behav. Neurosci. 4:17. doi: 10.3389/fnbeh.2010.00017

Copyright (c) 2010 Gomi, Sassa, Thompson and Itohara. This is an open-access article subject to an exclusive license agreement between the authors and the Frontiers Research Foundation, which permits unrestricted use, distribution, and reproduction in any medium, provided the original authors and source are credited. 